\title{
Qualification of a Full Plant Nodalization for the Prediction of the Core Exit Temperature through a Scaling Methodology
}

\author{
J. Freixa ${ }^{\mathrm{a}, 1, *}$, V. Martínez-Quiroga ${ }^{\mathrm{a}}, \mathrm{F}$. Reventós $^{\mathrm{a}}$ \\ ${ }^{a}$ Department of Physics and Nuclear Engineering, Technical University of Catalonia (UPC), Spain
}

\begin{abstract}
System codes and their necessary power plant nodalizations are an essential step in thermal hydraulic safety analysis. In order to assess the safety of a particular power plant, in addition to the validation and verification of the code, the nodalization of the system needs to be qualified. Since most existing experimental data come from scaled-down facilities, any qualification process must therefore address scale considerations. The Group of Thermal Hydraulic Studies at Technical University of Catalonia has developed a scalingup methodology (SCUP) for the qualification of full-scale nodalizations through a systematic procedure based on the extrapolation of post-test simulations of Integral Test Facility experiments. In the present work, the SCUP methodology will be employed to qualify the nodalization of the Ascó NPP, a Pressurized Water Reactor (PWR), for the reproduction of an important safety phenomenon which is the effectiveness of the Core Exit Temperature (CET) as an Accident Management (AM) indicator. Given the difficulties in placing measurements in the core region, CET measurements are used as a criterion for the initiation of safety operational procedures during accidental conditions in PWR. However, the CET response has some limitation in detecting inadequate core cooling simply because the measurement is not taken in the position where the cladding exposure occurs. In order to apply the SCUP methodology, the OECD/NEA ROSA-2 Test 3, an SBLOCA in the hot leg, has been selected as a starting point. This experiment was conducted at the Large Scale Test Facility (LSTF), a facility operated by the Japanese Atomic Energy Agency (JAEA) and was focused on the assessment of the effectiveness of AM actions triggered by CET measurements. The steps of the SCUP methodology are presented: post-test calculation, scaling effect analysis and design effect analysis. The Ascó NPP nodalization has shown to be qualified for the simulation of the involved phenomenology. The final step of the work presented here was to adapt the boundary conditions to a more realistic situation taking place in the Ascó NPP. CET and Peak Cladding Temperature (PCT) readings were seen to present large differences similarly as it occurred in the ROSA-2 Test 3. When the CET reached the safety criteria, the PCT measured was in the range of $[777,906] \mathrm{K}$ depending on which CET measurement was credited.
\end{abstract}

Keywords: PWR, CET, scaling, SBLOCA, ROSA

\section{Contents}

1 Introduction $\quad 2$

1.1 The UPC scaling-up methodology $(\mathrm{SCUP}) \ldots \ldots \ldots \ldots \ldots \ldots$

2 Selection of the scenario $\quad 6$

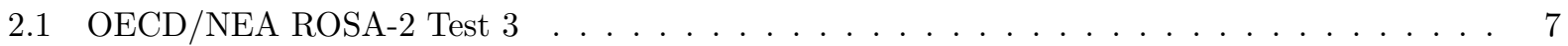

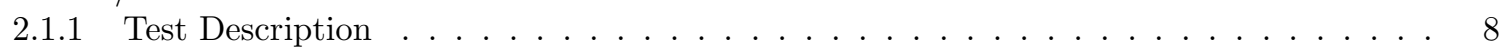

\footnotetext{
*Corresponding author. Tel.: +34-934017454.

Email addresses: jordi.freixa-terradas@upc.edu (J. Freixa), victor.martinez.quiroga@upc.edu (V. Martínez-Quiroga), francesc.reventos@upc.edu (F. Reventós)
} 
2.2 The ROSA/LSTF RELAP5 nodalization . . . . . . . . . . . . . . . . . . . . . . 9

2.3 Post-test calculation of the ROSA-2 Test $3 \ldots \ldots \ldots \ldots \ldots \ldots$

2.4 Lessons learned . . . . . . . . . . . . . . . . . . . . . . . . . . . . . . . . . 13

3 Ascó NPP RELAP nodalization 13

4 Qualification of the Ascó NPP nodalization $\quad 15$

4.1 Scaling Considerations . . . . . . . . . . . . . . . . . . . . . . 15

4.2 Idealized Scaling . . . . . . . . . . . . . . . . . . . . . . . . . . 16

$4.3 \mathrm{kv}$ scaled calculation . . . . . . . . . . . . . . . . . . . . . . 16

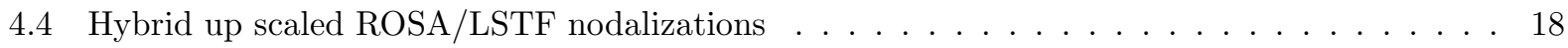

4.4 Volume of SG primary side . . . . . . . . . . . . . . . . . . . 18

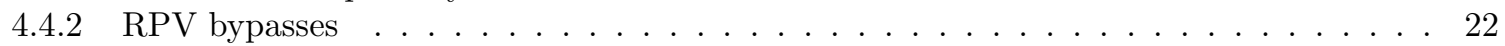

4.5 CET versus PCT . . . . . . . . . . . . . . . . . . . . . . . . 22

4.6 Realistic conditions in the Ascó NPP . . . . . . . . . . . . . . . . . . . 22

5 Conclusions

\section{Introduction}

Integral test facilities (ITF) are experimental facilities that reproduce the overall behavior as well as the interactions of the system components of a Nuclear Power Plant (NPP). The experimental results obtained at ITFs can be used to validate the performance of thermal-hydraulic (TH) system codes under conditions similar to those expected in accidental situations in actual NPPs. The use of ITFs was introduced as a response to the nuclear industry needs of analyzing NPP accident scenario under safe and cost assumable conditions. Hence, the target of the ITF design is to achieve a compromise between similarity with the NPP and economical costs. This is only feasible by reducing the geometrical dimensions according to a scaling approach. The different scaling criteria that are used for designing ITFs were summarized by Navahandi et al. (1979) in three different approaches:

- linear scaling: it is a technique whereby linear dimensions of the test facility are directly reduced by a fixed scale factor, relative to the reference NPP. The main advantage of the linear approach is that timing of events are directly reduced by the same factor. On the contrary, accelerations need to be scaled by the inverse of the time factor, and rated controlled phenomena (such as flashing heat and mass transfer, or flow regime transitions) are also distorted in time relative to the reference NPP.

- time preserving -or power to volume scaling-: this method is based on preserving power and flow distributions as well as time. It requires the ratio of the power in the ITF divided by the NPP power be equal to the ratio of the ITF volume divided by the NPP volume. Volume of each one of the components of the facility is scaled-down by reducing the area with this ratio and keeping its relative elevation. With an idealized power to volume scaling, time scale, fluid mass, energy distributions, velocities, accelerations and lengths are preserved.

- Idealized time preserving: it is a resemble of the time preserving scaling. Designer has more flexibility for modifying the geometries of those components for which local TH phenomena have a significant weight in the overall behavior of the system. Anyhow, geometrical readjustments must be always done without distorting the time scale.

- Finally, it is worth mentioning that new ITFs, like PUMA, ATLAS, or IIST, have been designed following the Ishii three level scaling approach (Ishii et al., 1998).

Historically, the power to volume scaling theory has been employed in most ITFs and has proved to be the one of the most adequate approach to face the scaling of complicated geometries. However, a "perfect" 
scaling of an intricate system is rather difficult if not impossible. In nuclear systems, most of the scaling distortions emerge when gravitational forces are of the same order of magnitude as inertial forces (usually during transient or accidental scenarios). In this situation, the influence of gravitational forces will be different for horizontal and vertical pipes and the perfect scaling of both pipe orientations with a single scaling approach will not be possible. In addition, the overall behavior of the NPP system become more dependent on local phenomena. Hierarchical methodologies have been developed (Zuber, 1991; Zuber et al., 2005) in order to identify the most relevant and minimize the impact of those irrelevant, but it becomes clear that ITF experimental results cannot be directly extrapolated to the NPP scale for safety analysis. Otherwise, the results of the ITF experiments can be used to validate system codes and derive modeling guidelines by means of post-test calculations of the experiments. Finally plant-scaled calculations at the NPP level will be needed to close the loop (NPP design, ITF experiment, ITF simulation, NPP simulation).

Plant-scaled calculations (called Kv-scaled analysis (D'Auria and Galassi, 2010)) are strongly involved in the qualification process of NPP nodalizations. The basic principle is to adjust the boundary conditions of an NPP nodalization to the experimental conditions of an ITF test. Plant-scaled calculations permit a qualitative comparison of the behavior of both systems under the same conditions. In this way it is possible to check the capabilities of an NPP nodalization and to improve them if required. Several plant-scaled calculations have been done during recent years (Martinez-Quiroga et al., 2014; Pla et al., 2007; Petelin et al., 2007; Freixa and Manera, 2011). Kv-scaled analysis have been demonstrated as a great tool for identifying counterpart phenomena and modeling deficiencies. On the other hand, it is worth to mention that this technique will finally depend on the expert judgment of the analyst and his knowledge on the scaling issue. In this sense, a novel scaling methodology has been developed at the Technical University of Catalonia (UPC) for supporting, justifying and demonstrating the discrepancies reported by the analyst, and the improvements that will be applied to the NPP nodalization.

\subsection{The UPC scaling-up methodology (SCUP)}

The UPC scaling-up methodology (SCUP methodology) is a systematic procedure for qualifying NPP nodalizations taking advantage of the experience acquired through the post-test analysis of )integral test facility (ITF) experiments. It is devoted to the nodalization qualification, which implies that the methodology can only be applied to those phenomena that have been well reproduced on ITF post-test analysis; and that the scaling analysis are only performed through code simulations. A diagram of the methodology is shown in Figure 1.

The SCUP methodology is a systematic procedure for qualifying NPP nodalizations taking advantage of the experience acquired through the post-test analysis of ITF experiments. It follows the general guideline given in the UMAE methodology (D'Auria et al., 1995), but an important development has been performed in order to identify and justify discrepancies that appear between counterpart simulations at different scales and designs. It is devoted to the modeling qualification, which implies that the methodology can only be applied to those phenomena that have been well reproduced in ITF post-test analyses, and that scaling analyses are only performed through code simulations (and do not involve experimental data).

There are two main factors that affect scaling up of ITF post-test simulations:

- The scaling-down criterion used for the design of the ITF.

- The differences of configuration between the ITF and the NPP.

In order to analyze both, SCUP uses two approaches, "scaled-up nodalizations" and "hybrid nodalizations." It is crucial that they are not confused with the approaches previously presented for assessing Kv-scaled calculations. The so-called "scaled-up nodalizations" analyze the effect of the ITF scaling criterion in a scaled-up calculation. On the other hand, the "hybrid nodalizations" are defined as modified scaled-up ITF nodalizations in which some components have been adjusted to resemble the configuration of the NPP components. The aim is to evaluate the influence of each feature of the configuration on the ITF simulation results irrespective of the scale.

The SCUP methodology is shown in Figure 1. The procedure is divided into several steps which are described hereafter: 


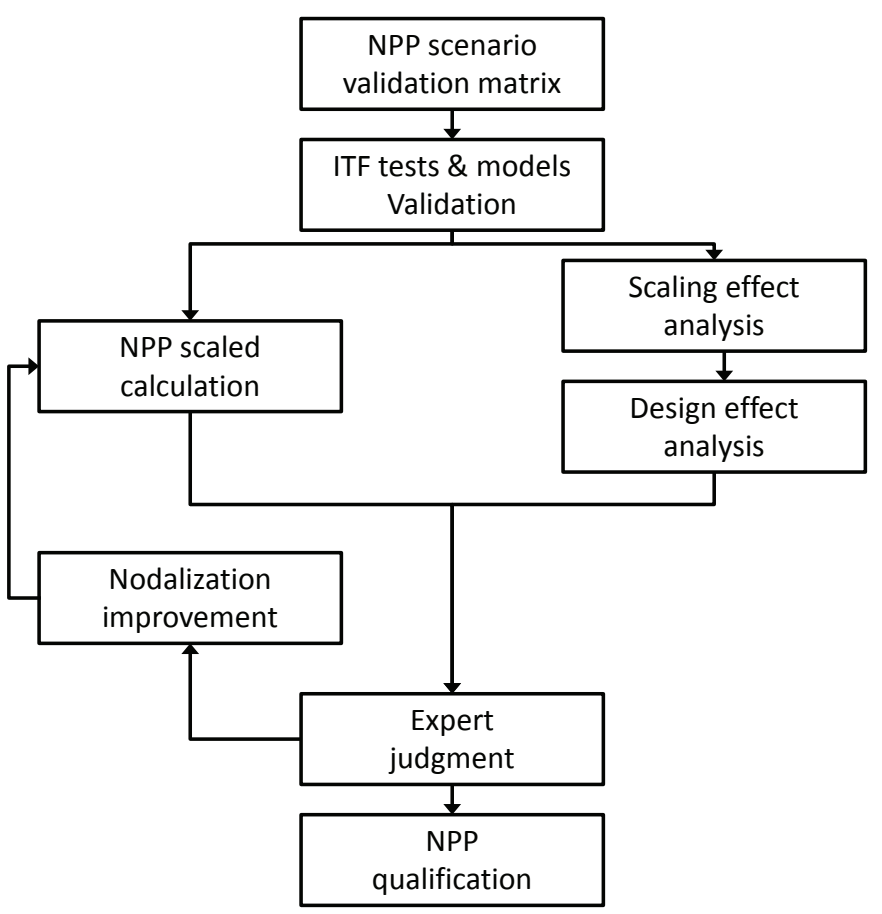

Figure 1: UPC scaling-up methodology

1. To identify a specific scenario for qualifying NPP nodalizations with ITF tests that reproduces its related phenomena "NPP scenario validation matrix".

2. To validate ITF nodalizations and ITF tests selected in the NPP validation matrix "ITF test \& models Validation".

3. To perform a preliminary Kv-scaled calculation with the NPP nodalization "NPP scaled calculation".

4. To analyze and establish the scaling and design effects in the simulation results by using generated scaled-up and hybrid nodalizations "Scaling effect analyses" and "Design effect analyses".

5. To perform an expert judgment by comparing the results of step (3) combined with conclusions of step (4) "Expert judgment".

NPP Scenario Validation Matrix The SCUP methodology requires the analyst to decide the type of scenario for which he wants to validate the NPP nodalization. Once the scenario has been selected, three main features have to be analyzed: the relevant TH phenomena occurring in the selected scenario, the design of the ITFs employed in the analysis, and the choice of ITF experiments. The aim is that the analyst finds ITFs with similar design to his NPP nodalization in which selected tests include the TH phenomena related to the specific scenario. Once the TH phenomena have been identified and the most convenient ITFs have been chosen, an "NPP scenario validation matrix" must be defined in order to ensure which phenomena can be tested by system codes. In this step it is important to pay attention to counterpart tests (tests with identical boundary conditions performed at facilities at different scales) because they allow to check, for different scales and designs, if the codes and the ITFs nodalizations can reproduce the same phenomena. This will not ensure that these phenomena can be extrapolated to the NPP scale, but it will be very effective for translating ITF modeling experience to NPP nodalization qualification because the analyst can evaluate whether the same modeling criteria have been used for different scales and designs. In the present work, this step is presented in Section 2. 
ITF tests and models validation The aim of this step is to ensure the quality of the results and to draw conclusions on code modeling. The work of the analyst should therefore be focused on (a) qualifying the ITF nodalizations for several tests beyond those selected in the validation matrix, and (b) assuring the robustness of the nodalization to minimize user effect and compensating errors. Once the ITF nodalization has been qualified and the required tests of the validation matrix have been simulated, phenomena that have been validated for at least two facilities at different scales and designs can be used for qualifying NPP nodalizations. The modeling guidelines derived in both cases need to be consistent. To achieve this, expert judgment will be essential. If counterpart tests have been validated for the same phenomena with the same modeling conclusions, a Kv-scaled calculation and scaling and design effect analyses will be performed for the counterpart test in which the design of the ITF is closest to the NPP nodalization. This step was already performed and presented in (Freixa et al., 2015).

NPP scaled calculation The aim of this step is to perform a calculation with the NPP model of an equivalent conditions of the ITF experiment. This type of simulations are commonly known as "Kv-scaled calculations", they have been previously described as system code simulations in which defined ITF test conditions are scaled up to an NPP nodalization in order to reproduce the same scenario. As regards to the SCUP methodology, Kv-scaled is a sole calculation with two aims, (a) to check the applicability of the ITF test in the NPP nodalization for phenomena that have been validated in post-test analyses, and (b) to be a reference for justifying as an expert judgment those discrepancies that appear in comparison with the results of the post-test analysis. Therefore, the Kv-scaled calculation must not undergo any modification during scaling and design effect analyses. Only if the expert judgment considers that the NPP must be improved should a second calculation be carried out in order to qualify the NPP nodalization improvements. This step is presented in Section 4.3.

Scaling effect analyses Scaled-up simulations must be performed in order to obtain a final idealized ITF scaled-up nodalization in which the effects of the scaling are minimized. To analyze the scaling effect, several "scaled-up" nodalizations must be generated using the calculated NPP scaling factors associated to the ITF design scaling-down criterion. The first nodalization has to be a regular scaled-up nodalization in which the scaling-down criteria is applied without any modification of the possible scaling distortion sources. A comparison with the ITF post-test simulation will show the effect of the scaling in the results. Whenever any distortion is detected, the analyst must perform another scaled-up nodalization without the scaling distortion source. Comparison with the ITF post-test calculation and the regular ITF scaled-up nodalization allows the effect of this specific scaling distortion source to be observed. This step must be repeated for all the scaling distortions detected until the user achieves an idealized scaled-up nodalization in which the analyzed phenomena are simulated in the same way as in the ITF post-test analysis. In this sense,"Scaled effect analyses" must be a guarantee that "Design effect analyses" will be carried out a posteriori without scaling distortions. In the present work, this step is carried out as described in Section 7 .

Design effect analyses The analyst must be able to justify the discrepancies that appear in a plant scaled calculation by means of the differences in design between the ITF and the NPP. In this sense, hybrid nodalizations are compared with the plant scaled calculation and the idealized scaled-up nodalization obtained from the scaling effect analyses. In hybrid nodalizations, selected components that present significant design differences are transferred from the NPP nodalization to the ITF idealized scaled-up nodalization obtained in the "Scaling effect analyses". This permits to evaluate the effect of each selected component on the results. The work of the analyst in this step has to be focused on two main features:(a) to identify which components and differences in the configuration might affect the phenomena to be validated, and (b) to develop a group of hybrid nodalizations in series for detecting sources of design distortion. Each component has to be added individually to the previous hybrid nodalization in order to distinguish which components may cause a distortion of the results and which do not. Although some discrepancies could be justified by two or more combined sources of design distortion, it will not be necessary to evaluate them separately as all of them are part of the NPP nodalization. Sequential analyses reveal both the effect of each component and that of them all together. This step is reproduced in Section 4.4 of the present publication.

Expert judgment Once the design effect analyses have been concluded, the analyst has valuable information about the NPP components that can explain observed discrepancies between Kv-scaled calculation and ITF post-test simulation. When such components are identified, their specification must be throughly 
checked and the analyst must ensure that these components have been consistently modeled. If the specifications of the components are well transcribed, the analyst, bearing in mind his ITF modeling know-how, has to judge the significance of the modeling details of the component for the tested phenomena in the specific scenario. If after expert judgment, it is considered that a nodalization improvement is required, a second plant scaled calculation will be necessary, comparing its results with the idealized scaled-up nodalization and one new hybrid nodalization for the new component. Otherwise, it will be considered that the NPP nodalization is qualified for these phenomena. Finally, when all the NPP validation matrix phenomena are validated, the NPP nodalization will be qualified for plant applications and support to plant operation in the specific scenario. This part is explained in Section 4.4.

Further information about each one of these steps and the SCUP methodology was given by (MartinezQuiroga et al., 2014; Martinez-Quiroga and Reventos, 2014). In the present paper, the results and simulations of an ITF will be used with the SCUP methodology to qualify a RELAP5 model of the Ascó NPP, a Westinghouse 3-loop pressurized water reactor. Once the nodalization has been qualified for the involved phenomena, a preliminary analysis of the particular scenario is introduced. This study evaluates the effectiveness of the actual NPP Emergency Operational Procedures (EOPs) as well as the Severe Accident Management Guidelines (SAMG) during a core heat-up phase.

\section{Selection of the scenario}

The main purpose of the SCUP methodology is to qualify NPP nodalizations for Design and Beyond Design Basis Accidents (DBA and BDBA). For these transients there is limited NPP data and experiments from ITFs are of great value for validating the modeling criteria of actual utilities. For the present qualification process, Test 3 of the OECD/NEA ROSA-2 project, an experiment at the Large Scale Test Facility has been chosen. The main reasons for this selection were:

- Relevance to safety analysis. In 2010, the Committee on the Safety of Nuclear Installations (CSNI) issued a report on the effectiveness of the core exit temperature (CET) measurements in pressurized water reactors (PWR) (Tóth et al., 2010). The CSNI indicated the need to investigate the problem of the scaling issue involving CET measurements and how to extrapolate the experimental results to commercial PWR reactors. CET measurements play an important role in the sequence of actions during accidental conditions in PWRs. Given the difficulties in placing measurements in the core region, CET readings are used as criterion for the initiation of operational procedures because they can indicate a core heat up scenario (Tóth et al., 2010). However, the CET response have some limitation in detecting inadequate core cooling and core uncovery, this is simply because the measurement is not taken in the position where the cladding temperature excursion occurs and the superheated steam is generated. Therefore, differences between the CET and the peak cladding temperature (PCT) are expected and thus, core uncovery will be unnoticed during a certain period of time. Assessing capabilities of system code to simulate the relation between the CET and the PCT is of main importance in the field of nuclear safety for PWR power plants.

- Comprehensive coverage of important phenomena. The SCUP methodology requires the identification of the most relevant phenomena and the capabilities of system codes to represent them. Table 1 is a proposal by (Martinez-Quiroga et al., 2014) of PWR SBLOCA/IBLOCA validation matrix based on the phenomena that were reported in the CSNI matrices (Annunziato et al., 1996). It links the main phenomena with a minimum set of experiments/facilities that reproduces them. A wide range of these phenomena were qualified with success for the simulations of the PKL and the LSTF counterpart experiments (ROSA-2 Test 3). In addition, relevant conclusions were reported by Freixa et al. (2015) about the modeling criteria to correctly reproduce the CET vs PCT correlation. By chosing this experiment, it is possible to extrapolate all this knowledge to the Ascó NPP nodalization and qualify it for simulating properly almost all phenomena linked to SBLOCA and IBLOCA scenarios.

- Confidence of the simulation results: as it is described in section 2.3, the simulation of the ROSA-2 Test 3 showed a close agreement with the experimental data. 


\begin{tabular}{|c|c|c|c|c|c|}
\hline \multirow[b]{2}{*}{ Test phenomena } & \multicolumn{2}{|c|}{ Counterpart Tests } & \multicolumn{2}{|c|}{ Counterpart Tests } & \multirow[b]{2}{*}{$\begin{array}{l}\text { ROSA } 2 \\
\text { Test } 1\end{array}$} \\
\hline & $\begin{array}{l}\text { PKL III } \\
\text { G7.1 }\end{array}$ & $\begin{array}{l}\text { ROSA 2 } \\
\text { Test } 3\end{array}$ & $\begin{array}{l}\text { LOBI } \\
\text { BL-34 }\end{array}$ & $\begin{array}{l}\text { LSTF } \\
\text { SB-CL-21 }\end{array}$ & \\
\hline 1 phase natural circulation & & & $\mathrm{X}$ & $\mathrm{O}$ & \\
\hline 2 phase natural circulation & $\mathrm{X}$ & $\mathrm{X}$ & $\mathrm{X}$ & $\mathrm{O}$ & \\
\hline Reflux and condensation & $\mathrm{X}$ & $\mathrm{X}$ & $\mathrm{X}$ & $\mathrm{O}$ & \\
\hline Asymmetric loop behavior & $\mathrm{X}$ & & & $\mathrm{O}$ & \\
\hline Break flow & $\mathrm{X}$ & $\mathrm{X}$ & $\mathrm{X}$ & $\mathrm{O}$ & $\mathrm{X}$ \\
\hline Phase separation without mixture level formation & $\mathrm{X}$ & $\mathrm{X}$ & $\mathrm{O}$ & $\mathrm{O}$ & $\mathrm{X}$ \\
\hline Mixture level and entrainment on SG secondary side & $\mathrm{X}$ & $\mathrm{X}$ & $\mathrm{X}$ & $\mathrm{O}$ & \\
\hline Core mixture level & $\mathrm{X}$ & $\mathrm{X}$ & $\mathrm{X}$ & $\mathrm{O}$ & $\mathrm{X}$ \\
\hline Stratification in horizontal pipes & $\mathrm{X}$ & $\mathrm{X}$ & $\mathrm{X}$ & $\mathrm{O}$ & $\mathrm{X}$ \\
\hline Phase separation T-junction and effect on break flow & $\mathrm{X}$ & $\mathrm{X}$ & & $\mathrm{O}$ & $\mathrm{X}$ \\
\hline ECC-mixing and condensation & $\mathrm{X}$ & $\mathrm{X}$ & $\mathrm{X}$ & $\mathrm{O}$ & $\mathrm{X}$ \\
\hline Loop seal clearing & & & $\mathrm{X}$ & $\mathrm{X}$ & $\mathrm{X}$ \\
\hline Pool-formation in UP/CCFL & & & & $\mathrm{O}$ & $\mathrm{X}$ \\
\hline Core-wide void and flow distribution & $\mathrm{X}$ & $\mathrm{X}$ & & $\mathrm{O}$ & $\bar{X}$ \\
\hline Heat transfer in covered core & $\mathrm{X}$ & $\mathrm{X}$ & $\mathrm{X}$ & $\mathrm{O}$ & $\mathrm{X}$ \\
\hline Heat transfer in pre-uncovered core & $\mathrm{X}$ & $\mathrm{X}$ & $\mathrm{X}$ & $\mathrm{O}$ & $\mathrm{X}$ \\
\hline Heat transfer on SG primary side & $\mathrm{X}$ & $\mathrm{X}$ & $\mathrm{X}$ & $\mathrm{O}$ & $\mathrm{X}$ \\
\hline Heat transfer on SG secondary side & $\mathrm{X}$ & $\mathrm{X}$ & $\mathrm{O}$ & $\mathrm{O}$ & $\mathrm{X}$ \\
\hline Pressurizer thermalhydraulics & & & & $\mathrm{X}$ & \\
\hline Surgeline hydraulics & & & & $\mathrm{X}$ & \\
\hline 1 phase 2 phase pumps behavior & & & & $\mathrm{O}$ & \\
\hline Structural heat and heat losses & $\mathrm{X}$ & $\mathrm{X}$ & $\mathrm{X}$ & $\mathrm{O}$ & $\mathrm{X}$ \\
\hline \multicolumn{6}{|l|}{ Non-condensable gas effect } \\
\hline \multicolumn{6}{|l|}{ Boron mixing transport } \\
\hline CETvsPCT relationship & $\mathrm{X}$ & $\mathrm{X}$ & & & \\
\hline \multicolumn{6}{|l|}{ Nomenclature } \\
\hline $\mathrm{X}=$ totally reproduced & & & & & \\
\hline $0=$ partially reproduced & & & & & \\
\hline
\end{tabular}

Table 1: NPP SBLOCA/IBLOCA validation matrix

- Similarity: LSTF is based on a PWR Westinghouse design.

- Size: LSTF is the largest PWR ITF in the world, offering minimized distortions compared to the other facilities selected in the validation matrix.

\subsection{OECD/NEA ROSA-2 Test 3}

The OECD/NEA ROSA-2 project aims to resolve key light water reactor TH safety issues by using the ROSA/LSTF facility at the Japan Atomic Energy Agency (JAEA). ROSA/LSTF is an experimental facility operated by JAEA, it is designed to simulate a Westinghouse-type 4-loop 3,420 MWth PWR under accidental conditions (The ROSA-V Group, 2003). It is a full-height and $1 / 48$ volumetrically-scaled twoloop system with a maximum core power of $10 \mathrm{MW}$ (14\% of the scaled PWR nominal core power) and pressures scaled 1:1. Loops are sized to conserve volumetric factor $(2 / 48)$ and to simulate the same flow regime transitions in the horizontal legs (preserving $L / \sqrt{(} D)$ factor). The core power is distributed over 20 fuel assemblies with 3 different power peaking factors, all assemblies have the same cosine-shaped axial power distribution. 
Following an agreement between the OECD/NEA ROSA-2 and PKL-2 projects, two similar experiments were conducted at the ROSA/LSTF and PKL(Kremin et al., 2001) test facilities, to result in a set of counterpart experiments for the simulation at different scales and pressures of the same accidental configurations leading to core heat up and reflooding sequences.

In this frame, ROSA-2 Test 3 (Takeda et al., 2012) simulated a PWR hot leg SBLOCA as a counterpart test to a PKL experiment (Schoen et al., 2012). The main objective of the experiment was to analyze the reliability of core exit thermocouples which are utilized worldwide as an important indicator of core heat-up and to start an accident management operator action.

In addition to the differences in geometry, scale and design between the two facilities, the difference in the maximum allowed primary pressure between the two facilities further complicates the definition of the counterpart boundary conditions because the core uncovery and increase of the CET typically occur in the range of pressures from 60 to 80 bars. In order to model the event at the intended pressure and perform a counterpart experiment with the PKL facility, Test 3 of the OECD/NEA ROSA-2 project was divided in three phases: a high pressure transient as it would occur in a normal PWR, a conditioning phase to bring the facility to a pseudo-steady state at around 50 bars, and a low pressure transient where the same transient is reproduced once again at a lower pressure corresponding to the operational pressure of the PKL facility. In turn, the initial conditions of the PKL facility were set to the same conditions as those of the ROSA-2 Test 3 low pressure phase.

For the qualification process of the Ascó NPP only the results obtained at the ROSA/LSTF facility will be used. The SCUP methodology was already used to understand the scaling and design effects between the two facilities in the counterpart exercise (Martinez-Quiroga et al., 2014).

\subsubsection{Test Description}

The boundary conditions of the counterpart experiment are shown in Table 2, the high pressure transient was only performed in the ROSA/LSTF facility while the low pressure transient was carried out in both test facilities. The test is initiated by opening a valve located at the upper side of the hot leg with a throat opening of $1.5 \%$ of the cold leg area (Takeda et al., 2012). At the same time, loss of offsite power is assumed which leads to the shut down of the primary pumps and the unavailability of the high pressure safety injection (HPSI) and the main feedwater system. Due to the loss of coolant, a steep depressurization of the primary system takes place and the scram signal is reached. As a consequence, the main steam isolation valves are closed causing an increase of the secondary pressure. The set-points for the opening of the secondary side relief valves are soon reached and the secondary pressure oscillates around these setpoints following the intermittent openings and closings of the valve. Since HPSI is unavailable, the primary system is continuously loosing coolant. When the coolant level in the system decreases below the hot leg connection to the UP, the break flow turns into single phase steam flow. In this case the primary system pressure will decrease below the secondary pressure and core boil off will initiate. An increase of the cladding temperature and the CET will follow thereafter. The high pressure phase is ended when PCT reaches $750 \mathrm{~K}$ (this is an imposed boundary condition).

A conditioning phase is carried out after the high pressure transient to bring the system to a stable reflux condensation state at around 45 bars and a reduced primary coolant inventory. The main steam relief valve set-points are modified to bring the system towards these conditions. When the system is stabilized, the break valve is opened again and the low pressure transient begins. Further actions during this phase are:

- Initiation of SG secondary-side depressurization by fully opening the relief valves, and initiation of the auxiliary feedwater (AFW) system in both loops as Accident Management (AM) action. These actions are performed when the maximum core exit temperature reaches $623 \mathrm{~K}$.

- Initiation of Acc injection when the primary pressure reaches 26 bars.

- Initiation of the Low Pressure Safety Injection (LPSI) when the pressure in the lower plenum of the Reactor Pressure Vessel (RPV) reaches 10 bars. 


\begin{tabular}{|c|c|}
\hline Event & condition \\
\hline \multicolumn{2}{|c|}{ High pressure transient } \\
\hline Break opens & Time zero \\
\hline Generation of scram signal & Primary pressure $=12.97 \mathrm{MPa}$. \\
\hline Pressurizer (PZR) heater off & $\begin{array}{l}\text { Generation of scram signal or PZR liq- } \\
\text { uid level below } 2.3 \mathrm{~m}\end{array}$ \\
\hline $\begin{array}{l}\text { Initiation of core power decay curve simulation } \\
\text { Initiation of primary coolant pump coastdown } \\
\text { Turbine trip (closure of stop valve) } \\
\text { Closure of main steam isolation valve } \\
\text { Termination of main feedwater }\end{array}$ & Generation of scram signal \\
\hline Opening and closing of the SG relief valves & $\begin{array}{l}\text { SG secondary-side pressure }=8.03 / 7.82 \\
\mathrm{MPa}\end{array}$ \\
\hline Generation of SI signal & Primary pressure $=12.27 \mathrm{MPa}$ \\
\hline $\begin{array}{l}\text { Initiation of HPI coolant injection into RPV upper } \\
\text { plenum }\end{array}$ & $\begin{array}{l}\text { Maximum fuel rod surface temperature } \\
=750 \mathrm{~K}\end{array}$ \\
\hline \multicolumn{2}{|c|}{ Low pressure transient } \\
\hline Break opens & Low pressure transient initiates \\
\hline $\begin{array}{l}\text { Initiation of SG secondary-side depressurization by } \\
\text { fully opening SGRVs as AM action }\end{array}$ & $\begin{array}{l}\text { Maximum core exit temperature }=623 \\
\mathrm{~K}\end{array}$ \\
\hline Initiation of $\mathrm{AFW}$ in both loops & initiation of $\mathrm{AM}$ action \\
\hline Initiation of accumulator system & Primary pressure $=2.6 \mathrm{MPa}$ \\
\hline Initiation of low pressure injection system & $\mathrm{PV}$ lower plenum pressure $=1.0 \mathrm{MPa}$ \\
\hline
\end{tabular}

Table 2: Control logic of the counterpart experiment (Takeda et al., 2012)

\subsection{The ROSA/LSTF RELAP5 nodalization}

The ROSA/LSTF RELAP5 nodalization has been previously qualified for the OECD/NEA ROSA-1 Tests 3.13 .2 (Martinez-Quiroga et al., 2012a,b) and was later on improved for the simulation of Test 3 with modifications that were introduced to specifically improve the reproduction of the CET response. A detailed description of the simulation of Test 3 and the dedicated modifications was given by Freixa et al. (2015). The full model nodalization used in the present work is shown in Figure 2. The core and upper plenum regions were updated in order to better reproduce the radial power distribution in the core and other phenomena important for Test 3 of the ROSA/LSTF rig. The core region is simulated by 13 parallel channels with 20 axial nodes (the last two cells represent the region around the upper core plate). The 13 channels correspond to fuel assemblies or groups of fuel assemblies having the same power. Cartesian crossflows were used to distribute them radially. The 8 Control Rod Drive Tubes (CRGT) were modeling with 8 distinct pipes connected to the corresponding channel at the bottom and all connected to the same volume that represents the Upper Head (UH). 


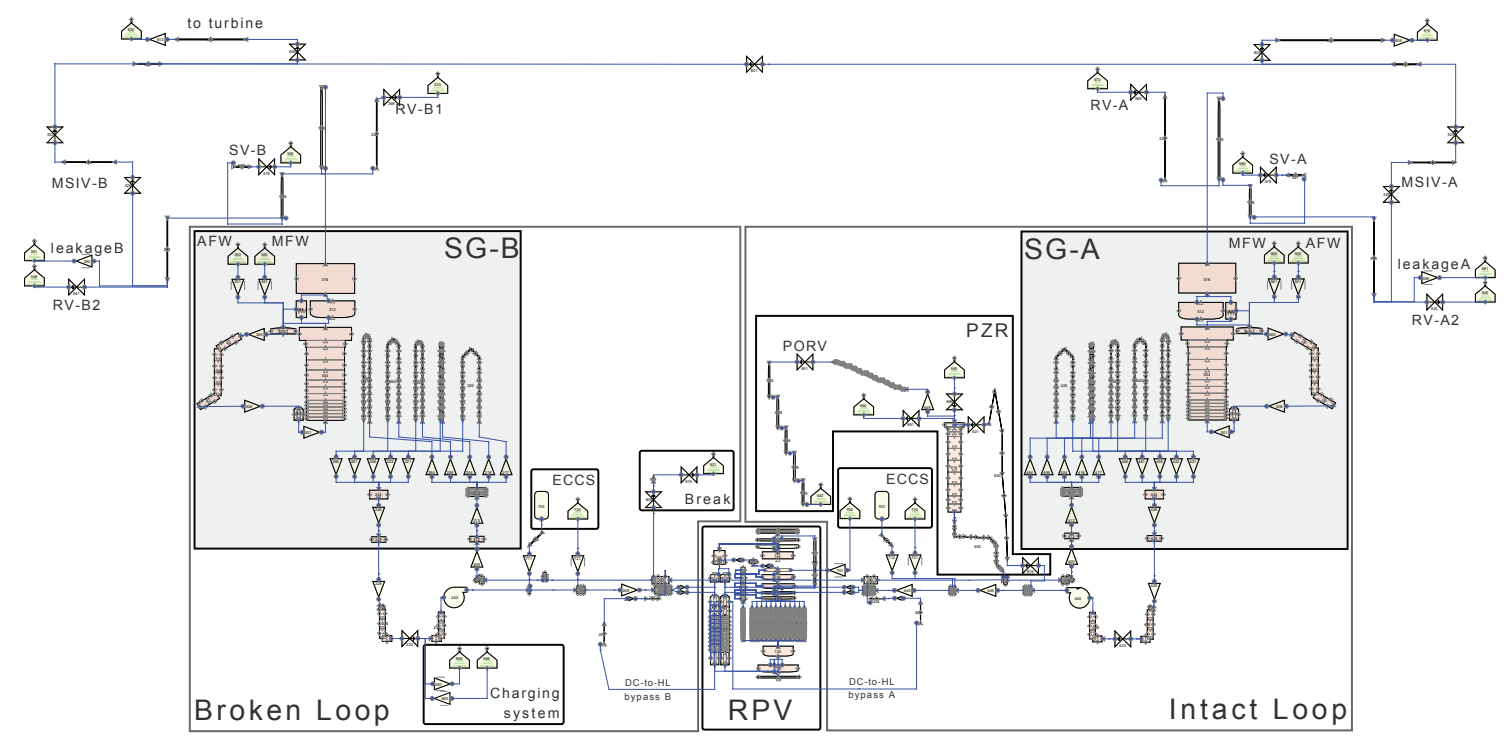

Figure 2: RELAP5 nodalization of ROSA/LSTF

\subsection{Post-test calculation of the ROSA-2 Test 3}

The most relevant results of the post-test calculation of the OECD/NEA ROSA-2 Test 3 are displayed in Figure 3, showing the primary and secondary pressures, maximum PCT, break flow and hot leg level and the RPV collapsed water levels. This set of variables will be used in the following sections for a visual evaluation of the simulations.

The results obtained are in quite close agreement with the experimental data. The primary and secondary pressures follow a similar evolution as in the experiment proving adequate performance of the choked flow in all its phases (subcooled, 2-phase and steam flow). There are no major differences to be reported. The RPV collapsed water levels are particularly well reproduced throughout the entire transient. This figure verifies the capacity of the code and the ROSA/LSTF model to reproduce the experiment.

Regarding the CET versus PCT issue, Figure 4 displays the maximum PCT in the core as a function of the CET for the ROSA experiment. This figure is of main importance because it compares the information seen by the operator (the CET measurements) and the maximum temperature found in the core. In this sense, the CET value is given in as many points as possible, this depends on the number of cells available in the core outlet (13 in this case). The experimental results is displayed by two sets of points: the first one corresponds to the thermocouple that detected the highest temperature (located above the hottest core zone) and the second set corresponds to the core exit thermocouple that detected the lowest temperatures (located at the periphery of the core outlet). The red dotted line corresponds to the hypothetical result where the CET is equal to the PCT. This line has been added to provide an estimation on the difference between the information available to the operator (CET measurement) and the actual situation in the temperatures of the core. The horizontal lines at the top are due to the sharp primary side depressurization which brings foamed fluid to the core and UP once the AM of SG relief valves aperture is triggered. This phenomenon quickly brings core exit temperatures to saturation, however PCT remains high for a very short period of time. This phenomenon was also observed in the experiment.

Further details on the post-test calculation of Test 3 given by Freixa et al. (2015). The rather good agreement between the calculation and the experiment is a good starting point to perform a scaling calculation for the Ascó NPP. 


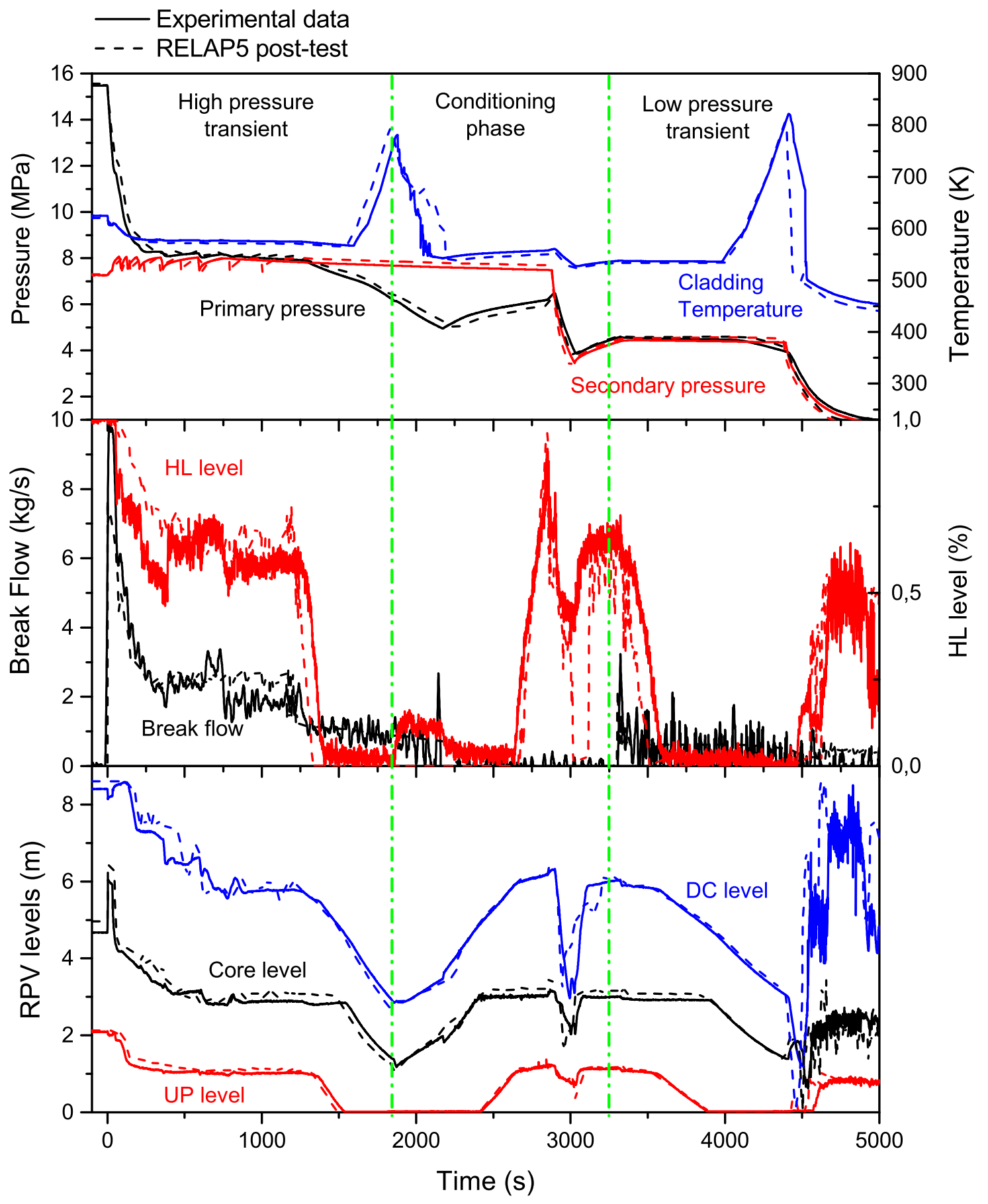

Figure 3: RELAP5 post-test results of the ROSA-2 Test 3 compared to the experimental data. From top to bottom: (1) primary and secondary pressure along with the cladding temperature, (2) break flow and hot leg level close to the break location and (3) RPV collapsed water levels. 


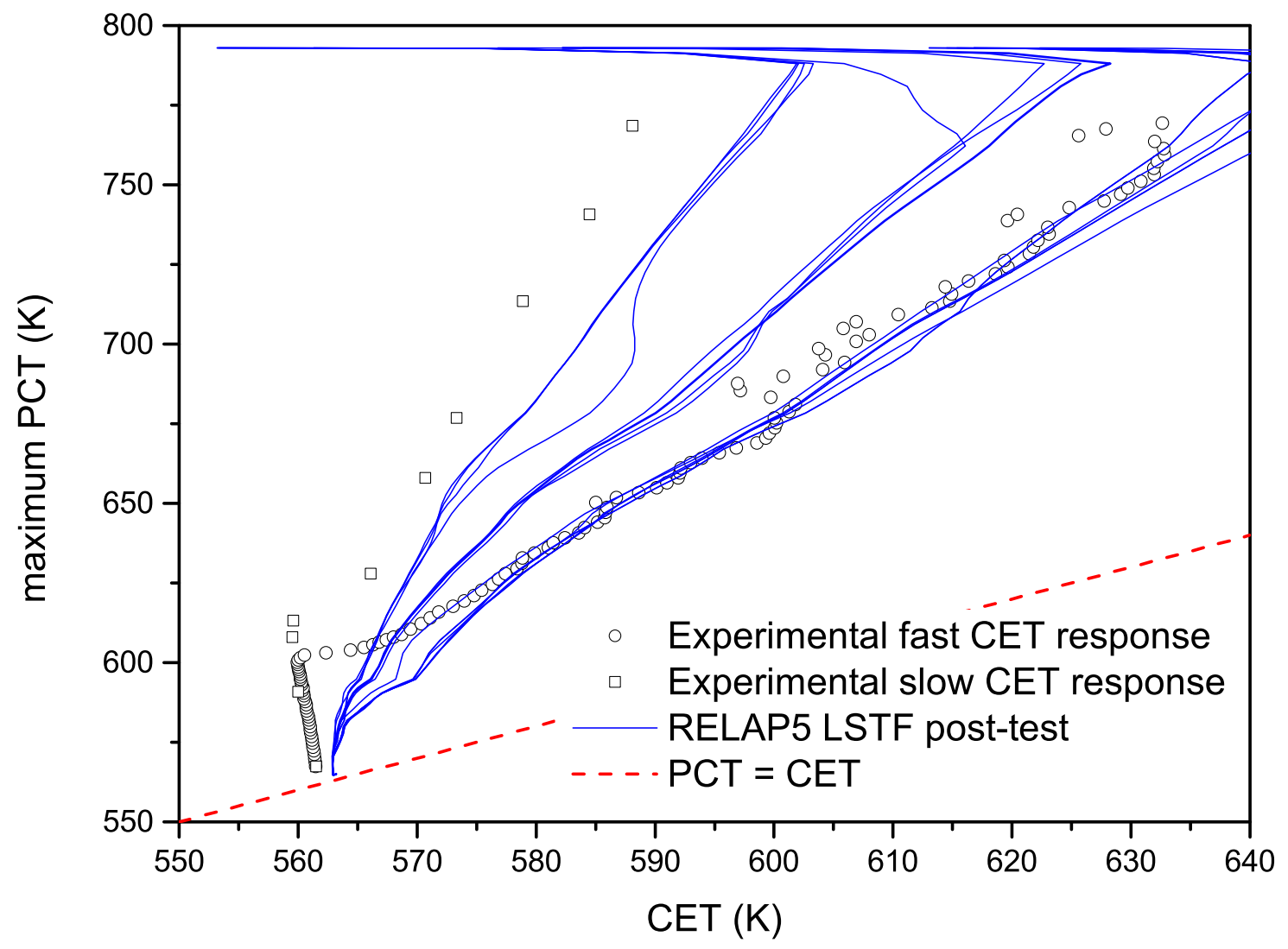

Figure 4: PCT as a function of the CET for Test 3 (experiment and post-test) 


\subsection{Lessons learned}

In order to reach a qualified post-test calculation some parts of the nodalization were modified. Details on these modifications were reported by Freixa et al. (2015). Three main aspects were identified to be crucial to correctly model the CET temperature: (1) a detailed modeling of the passive heat structures in the core and UP regions, (2) an accurate modeling of the geometrical aspects of the core and UP regions including the CRGTs and (3) the simulation of the TCs by using dedicated heat structures instead of the usage of the default steam temperatures provided by the code. A 3-D representation of the region could provide a good account of the heterogeneous conditions in the region. According to the SCUP methodology, these guidelines need to be implemented in the NPP nodalization.

The post-test calculation constitutes the first step in the SCUP methodology. The results have shown a close agreement in the loss of mass inventory, de-pressurizations of the systems and core temperatures. These three aspects could not be achieved without simulating with success the break mass flow, reflux and condensation processes, two phase natural circulation, phase separation without mixture level formation and horizontal stratification, core and SG mixture levels, off-take effect at the break junction, heat transfer processes in the core and SGs, and environment heat losses. All these phenomena constitute about $60 \%$ of those reported in Table 1. Hence, the qualification of an NPP nodalization with these results will guarantee that main phenomena of SBLOCA/IBLOCA scenarios are properly simulated within the intrinsic limitations of the models and correlations of the RELAP5 BE code.

\section{Ascó NPP RELAP nodalization}

Ascó NPP has two units; each of them is a three-loop PWR of Westinghouse design. The first unit is owned by ENDESA (100\%). Second unit is owned by ENDESA (85\%) and IBERDORLA (15\%). The units are located close to Tarragona, in the north east of Spain. The commercial operation of the plant started on December 1984. The actual nominal power of each unit is $2952.3 \mathrm{MWt}$ equivalent to $1028 \mathrm{MWe}$.

The model of the plant includes hydrodynamic elements (primary, secondary, safety systems and auxiliary systems), heat structures, and control and protection systems. The model has been subjected to a thoroughly validation and qualification process, which includes the simulation of transients occurred in the plant ((Pretel et al., 2001; Reventós et al., 2007)). Figure 5 shows a general view of the hydrodynamic part of the model.

Before the input model is qualified for the simulation of the selected scenario, the guidelines derived during the post-test calculation must be implemented in the Ascó NPP model. In order to correctly represent the relationship between PCT and CET, a detailed nodalization of the core region is needed (Freixa et al., 2015). The reason is because the CET temperature will strongly depend on the steam velocities and the heat transfer processes with the passive heat structures in the core and core outlet regions. A multi-pipe approach permits the correct representation of the core power and the location of the passive heat structures.

The core region and core outlet of the Ascó NPP input deck were renodalized following a similar approach as in the LSTF nodalization. The former 6 axial nodes were renodalized into 18 nodes. The single channel was split in 4 pipes (see Figure 6). Cross flow junctions were added between the zones. The criteria used to distribute the proportion of total area and volume of each pipe was carried out by dividing the core in power zones. The fuel assemblies were sorted according to their linear heat generation rates (LHGRs), and 4 zones were defined by grouping similar LHGR fuel assemblies. After that, the area proportion of each pipe was calculated by comparing the number of fuel rods in each zone to the total number of fuel rods. One additional heat structure was included to represent the hot rod; this structure was added to the hot zone 1 hydraulic channel. The first node of the UP was also re-nodalized, it was split in two axial nodes and 4 radial zones following the same criteria as for the core channels as shown in Figure 6.

In addition, the passive heat structures in the core and UP regions were nodalized according to the given guidelines. The core exit temperature measurements were simulated by heat structures with the material and size of a typical thermocouple. 


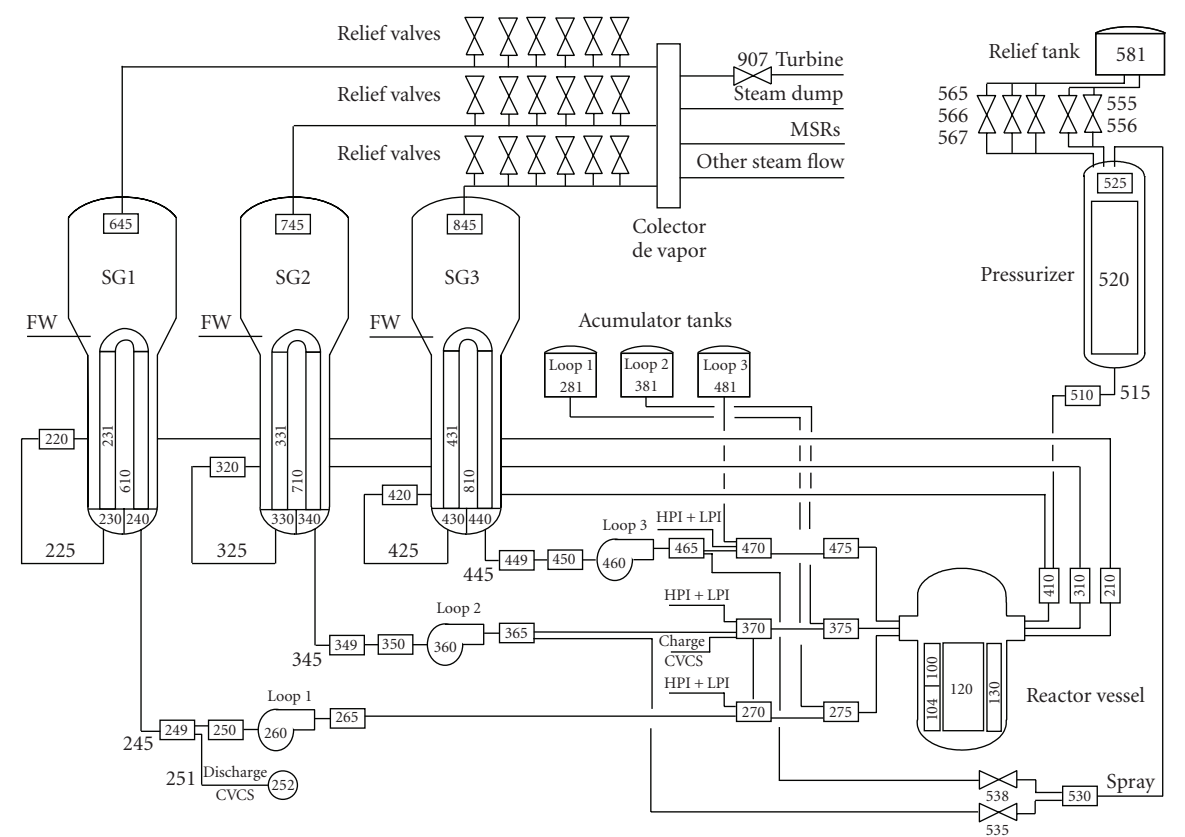

Figure 5: Diagram of the Ascó NPP nodalization for RELAP5

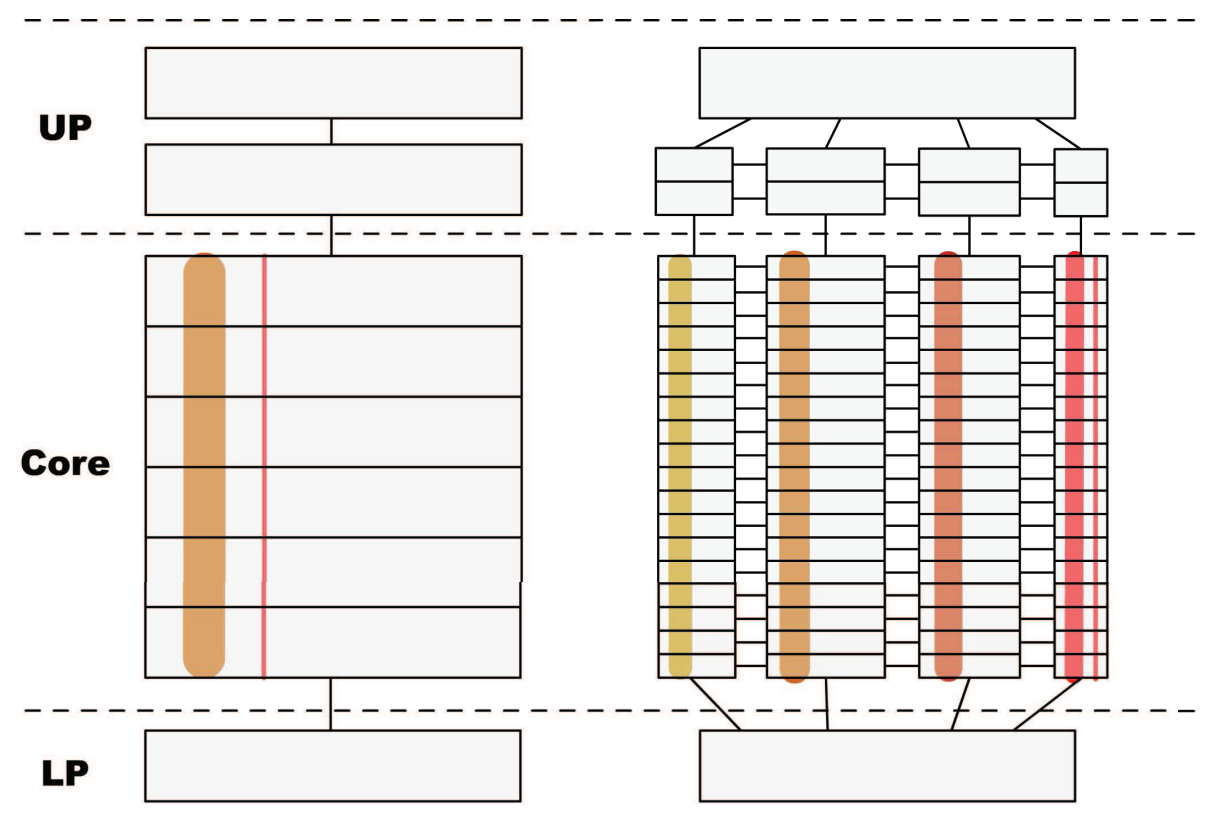

Figure 6: Renodalization of the core and upper plenum region for the Ascó NPP input deck 


\section{Qualification of the Ascó NPP nodalization}

The SCUP methodology will be applied in order to qualify the Ascó NPP nodalization for the selected scenario, in this case an SBLOCA in the hot leg. In particular, the attention will be focused on the evolution of the relation between the CET and the PCT during the core heat up phase.

Once the post-test simulation of the ITF has been carried out and the nodalization is considered to be validated, the SCUP methodology opens two paralel lines of work. On the one hand, the NPP nodalization will be adapted to perform a Kv scaled calculation of the proposed scenario (Section 4.3), this will be basically done by adjusting the boundary conditions of the NPP to those of the experiment. On the other hand, the ITF nodalization will go through the scaling (Section 7) and design (Section 4.4) effects analyses. The differences that have not been explained through the scaling and design effects analysis may require improvements of the NPP nodalization.

\subsection{Scaling Considerations}

As a first step, the scaling factors between the ITF and the NPP must be evaluated to assess the viability of the SCUP methodology. In addition, the analyst should define a scaling factor between the two designs that should be employed to set the boundary conditions of the $\mathrm{Kv}$-scaled calculation. Table 3 displays the scaling factors used in the design of ROSA/LSTF and the ones between ROSA/LSTF and the Ascó NPP. It can be noticed that even for the scaling of the reference plant there is a variability of the factors depending on the parameter, this is a direct consequence of the fact that a perfect scaling of a complex system is not possible. Most values are around 48 which is the design scaling factor, but some are considerably lower, for instance the volume of the loops. This means that the volume of the loops in ROSA/LSTF is proportionally larger than the one from the reference plant. In the case of the Ascó NPP, one can observe that two different scaling values prevail. The scaling factor observed for the parameters related to the RPV are around 39.0 and the values linked to the primary loops are around 36 . In order to define one single scaling factor, expert judgment is needed, and there is not just one correct answer. On the other hand, once one factor is selected, the derived scaling distorsions could be assessed with hybrid nodalizations if needed (it will be demonstrated in Section 4.4.1).

\begin{tabular}{lcc}
\hline Parameter & Scaling factor, reference plant & Scaling factor, Ascó NPP \\
\hline Core power & 47.9 & 41.2 \\
Total volume RPV & 47.8 & 39.8 \\
Core volume & 39.1 & 38.2 \\
Core flow area & 41.9 & 37.8 \\
Number of fuel rods & 50.5 & 39.0 \\
PZR volume & 42.5 & 36.2 \\
Hot leg $L /$ sqrtD & 1.0 & 0.944 \\
Volume of the loops & 39.2 & 36.0 \\
U-tube outer surface & 43.0 & 36.8 \\
Number of U-tubes & 48.0 & 36.38 \\
Volume of SG primary side & unknown & 32.8 \\
Volume of U-tubes & unknown & 35.0 \\
\hline
\end{tabular}

Table 3: Scaling factors between ROSA/LSTF and its reference plant compared to the scaling factors between ROSA/LSTF and Ascó NPP 


\subsection{Idealized Scaling}

In this step, the RELAP5 input deck used for the simulation of the ROSA-2 Test 3 was upscaled to the Ascó NPP size by making use of the in-house software PVST (further information was given by MartínezQuiroga (2014)). This software upscales all volumes and areas of the model with the desired kv value and allows to manage other important parameters like the Froude number in horizonatal components. Scaled-up nodalizations were generated as described in Section 1.1 in order to assess and delete the scaling effects of the enlarged simulation of the post-test. The Kv factor applied for this assessment was the same as the one used in the prior $\mathrm{Kv}$-scaled calculation (39).

As it is reported in (Martínez-Quiroga, 2014), for the Power to Volume method the scaling distortions associated to RELAP5 simulations are mainly related with the difference between the scaling factor applied to the hydraulic diameter $(\sqrt{K v})$ and the applied to the fluid surfaces and volumes $(\mathrm{Kv})$; hence discrepancies in the global behavior of the main TH parameters can be expected as a result of different environment heat losses, energy storage in passive structures, friction effects, and flow regime transitions. For this reason, the following two aspects have been considered in this process:

- The surface area of the passive heat structures has been scaled by the Kv factor instead of the typical $\sqrt{K v}$ used for a standard power to volume approach. In this way, the heat losses will be preserved.

- The hydraulic diameters and the length of the hot legs are scaled so that the Froude number is preserved $(L / \sqrt{D}$ is preserved).

In Figure 7 the results of the post-test calculation and the upscaled model are compared. The results obtained at the reactor scale are in very close agreement with the post test calculation. Thus, no other scaling distortions are expected to have a worthy effect for this particular scaled-up simulation, and an idealized scaled-up nodalization can be set for independently assessing the effects of the design with hybrid nodalizations. This two simulations also show that the ROSA/LSTF design has a good scalability.

Finally, it is worth to mention that during this step of the methodology, a modification of the input deck was needed in order to guarantee the scalability of the code physical models. An initial comparison of the post-test and the scaled-up model showed a distortion in the RPV water levels. This distortion was found to be related to a misinterpretation of the code manual that led to different results in the interphase drag forces in the core. The interphase drag depends on the hydraulic diameter which is independent on the scale. When the hydraulic diameter is not defined at junctions, the code calculates it from the flow area path of the two adjacent cells rather than from the hydraulic diameter on the two adjacent cells. Because the Hd was not defined in the core internal junctions, the resulting junction $\mathrm{Hd}$ depended on the scale. The junction $\mathrm{Hd}$ was then manually input and the two calculation reported practically the same results as shown in Figure 7. Therefore, it can be concluded that this initial step of the methodology brought up an improvement of the post-test calculation (the results shown in Section 2.3 already include this modification).

\section{3. $k v$ scaled calculation}

In this step the Ascó NPP RELAP5 model is adapted to simulate the same conditions as in Test 3. But even before this step is done, the lessons learned from the previous exercises are included in the Ascó NPP model:

- Multichannel approach is used for the core and UP regions

- Detailed definition of the upper core plate heat structure

- Simulation of thermocouple heat structures to represent core exit temperature

- Correct definition of Hd in the core junctions to fulfill scalability of the RELAP5 models

Once these modifications are implemented in the code the following boundary conditions are configured to perform a Kv scaling calculation: 


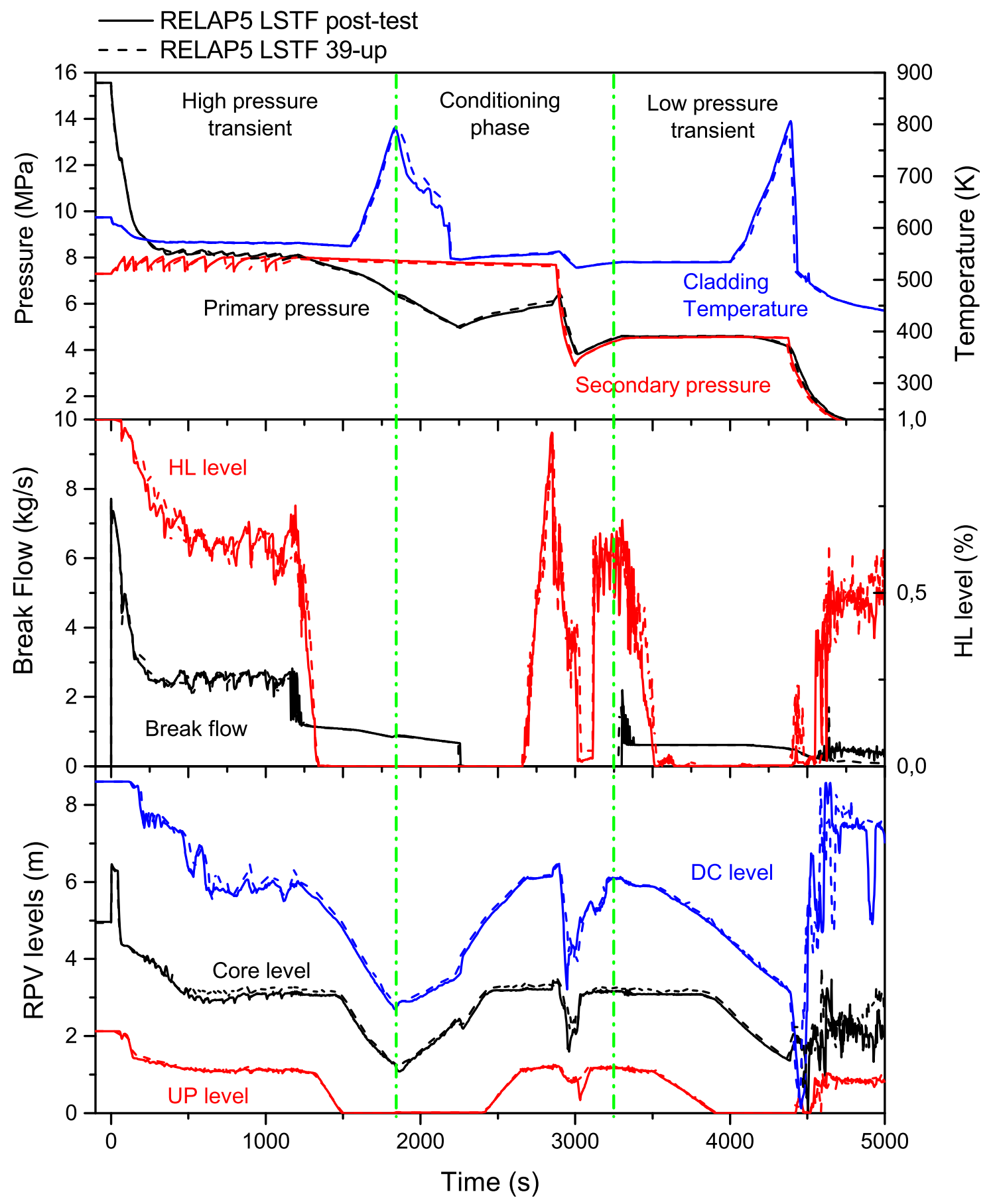

Figure 7: RELAP5 post-test and scaled-up (39) results for the ROSA-2 Test 3. From top to bottom: (1) primary and secondary pressure along with the cladding temperature, (2) break flow and hot leg level close to the break location and (3) RPV collapsed water levels. 
- Break nodalization. The same break nodalization as employed in the ROSA/LSTF RELAP5 nodalization.

- The same total core power as in the ideal scaling calculation is used, although the radial distribution of the Ascó NPP is maintained.

- The pumps coast down is the same as in the experiment.

- The initial conditions are adjusted to be the same as in the experiment. The initial PZR level is adjusted so that the volume of liquid is the same as in the ideal scaling calculation

- The secondary relief valves set points are modified to be the same as in the experiment. The area of the valves is modified to the same value as in the ideal scaling calculation.

The results are compared to the ideal scaling calculation in Figure 8. During the first 1000 seconds the two calculations show a good agreement however, the hot leg level where the break is located falls relatively earlier in the NPP calculation and so do the primary system water levels, leading to an advanced increase of the cladding temperatures. The depressurization of the system once the break transits from two phase flow to single phase vapor is faster. The evolution of the DC level shows particularly large distortions.

At this stage, the methodology suggests that these discrepancies need to be explained either by hybrid calculations or by improvements of the NPP model. The ideal scaling calculation is assumed to provide reasonably correct results given the fact that the post-test calculation was in very close agreement with the experiment.

\subsection{Hybrid up scaled ROSA/LSTF nodalizations}

In order to suppress any design difference that could cause distortions between the two calculations hybrid calculations have been performed.

The Ascó NPP model has only heat losses in the RPV region whereas the ideal scaling calculation simulates heat losses in the primary loops as well. In order to sort out this source of distortion, the heat losses in the primary loop of the ideal scaling model were removed. The calculation with and without heat losses of the ideal scaling calculation is shown in Figure 9. It can be observed that the effect of removing the heat losses is minimal. Indeed, heat losses at the NPP scale are assumed to have a small impact in this type of scenario. However, it is important to bear in mind that this does not mean that heat losses are not important for any type of scenario. In the present work, the model will be qualified without heat losses. If in the future, this model is to be used for scenarios where heat losses play an important role, the model will need to be reevaluated.

The Froude number in the hot leg is crucial for this experiment as the break flow will strongly depend on the stratification in the hot leg because the break is located on the upper side of the hot leg (MartinezQuiroga et al., 2014). The Froude number in the hot leg of the two models is still slightly different. In this hybrid calculation in addition to the deletion of the loop heat losses, the hot leg diameter and length is adjusted so both calculations have exactly the same Froude number.

The results obtained with this hybrid model are shown in Figure 10, it can be seen that this hybrid calculation does not change significantly the distortions. The modifications in the Froude number are very small, however, one could expect an impact by deleting the heat loses. The impact of the heat losses are only seen at the low pressure phase when the inertia provided by the passive heat structures are more relevant. This shows, that at this scale the impact of heat losses is low and the approach followed to simulate the NPP is consistent.

\subsubsection{Volume of $S G$ primary side}

There is a significant volumetric distortion between the two designs in the primary system. As shown in Section 4.1, the volume of the SG primary side is considerably different, the scaling factor for the volume in the SG plena and U-tubes are 32.8 and 35 instead of 39. This means that the volume of water above the reactor coolant line (hot and cold legs) is considerably lower in the Ascó NPP. This difference could explain 


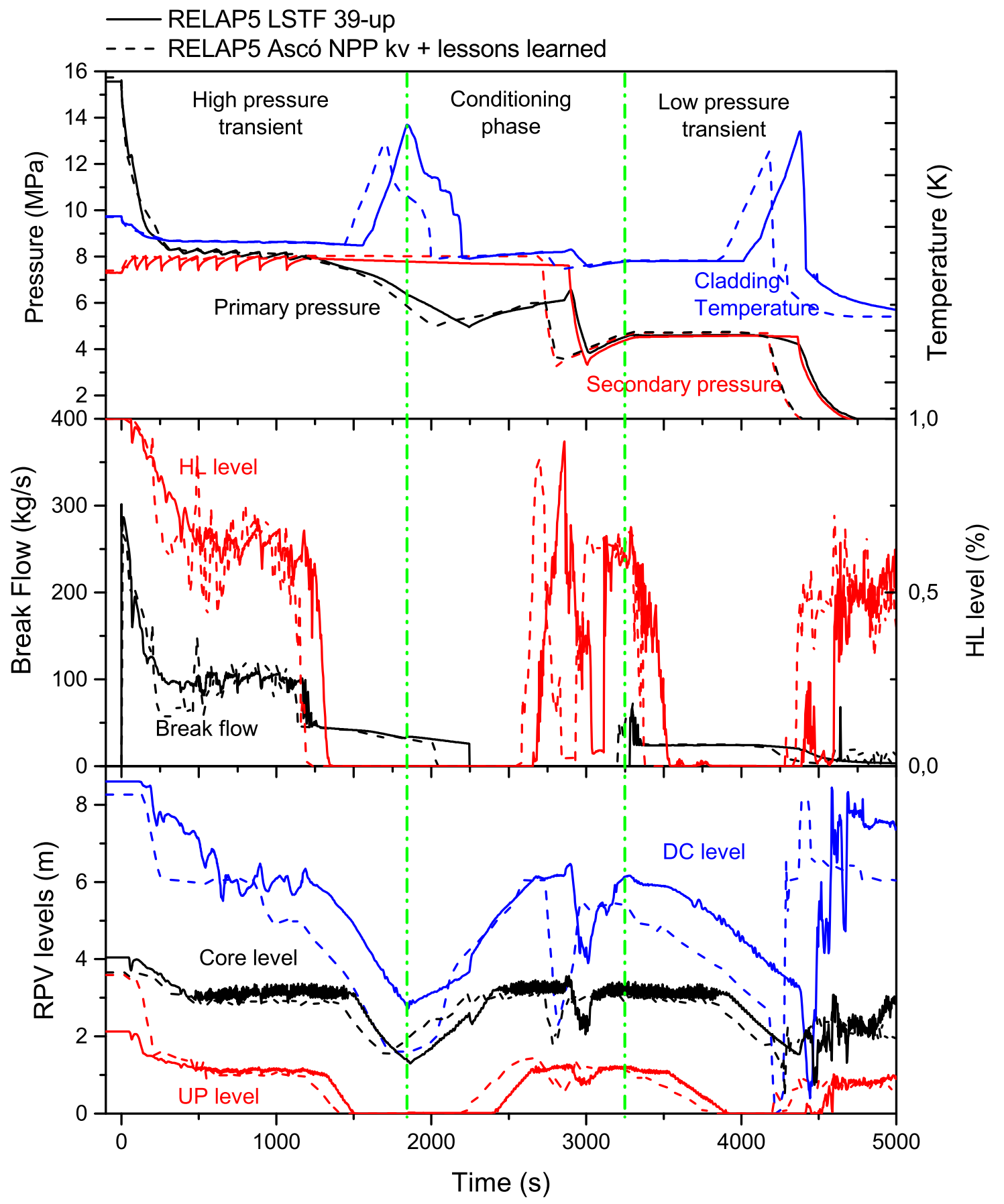

Figure 8: Comparison between the LSTF ideal scaled-up model and the Kv scaled calculation (Ascó NPP). From top to bottom: (1) primary and secondary pressure along with the cladding temperature, (2) break flow and hot leg level close to the break location and (3) RPV collapsed water levels. 


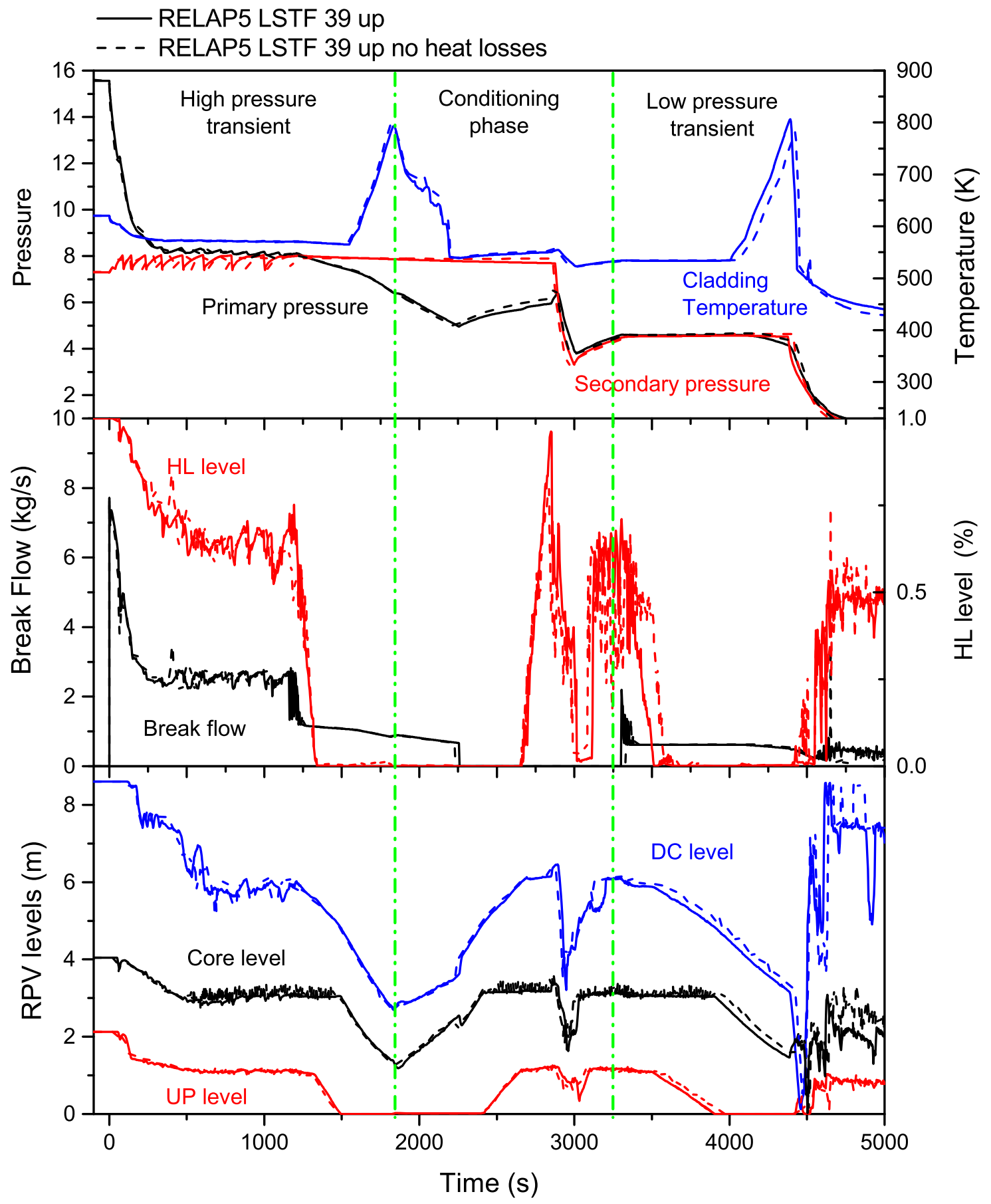

Figure 9: Comparison between the LSTF ideal scaled-up model with and without heat losses. From top to bottom: (1) primary and secondary pressure along with the cladding temperature, (2) break flow and hot leg level close to the break location and (3) RPV collapsed water levels. 


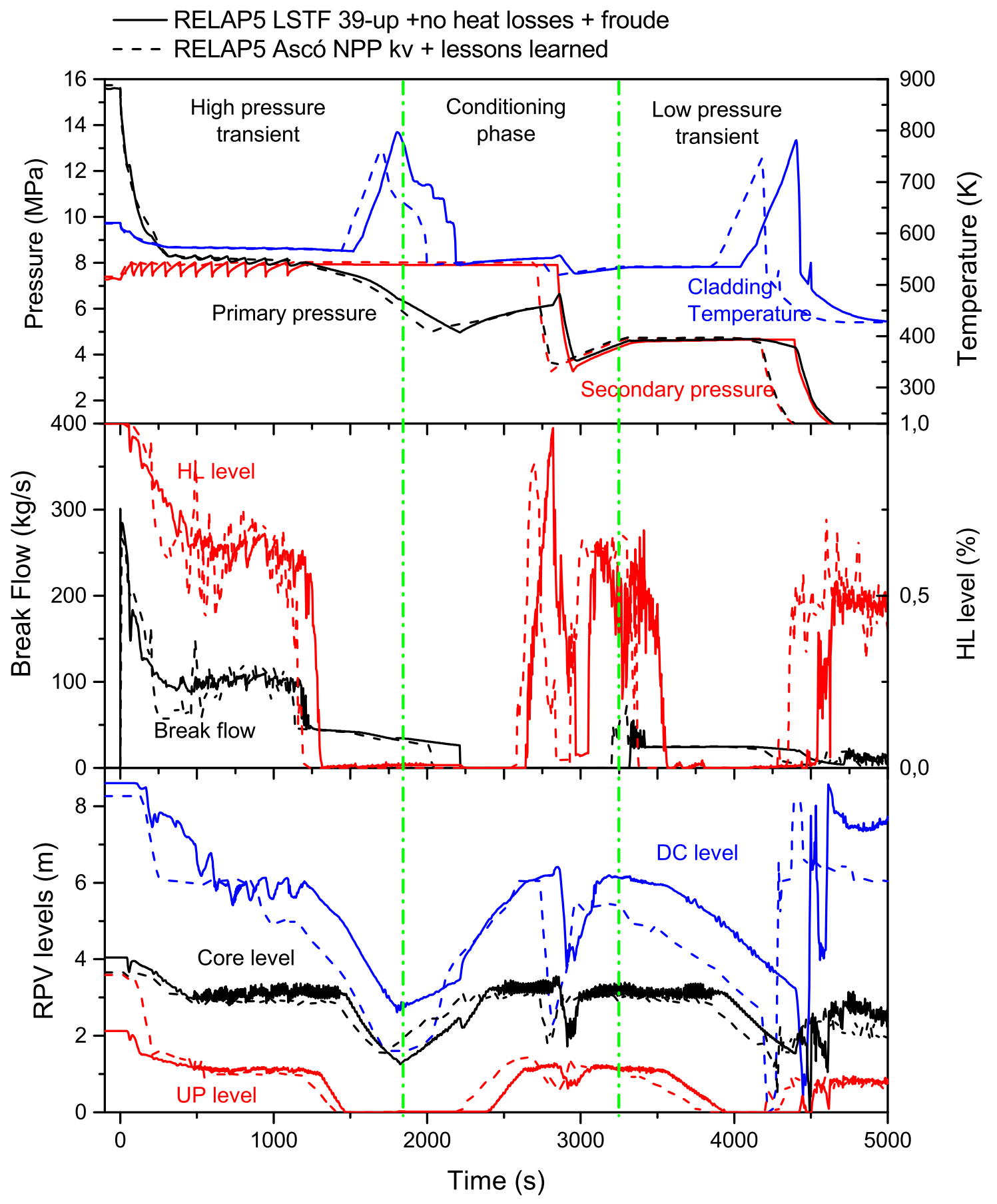

Figure 10: Comparison between the LSTF ideal scaled-up model (no heat losses, Froude number preserved) and the Kv scaled calculation (Ascó NPP). From top to bottom: (1) primary and secondary pressure along with the cladding temperature, (2) break flow and hot leg level close to the break location and (3) RPV collapsed water levels. 
the time difference in the voiding of the hot leg and the transition in break flow. A hybrid model of the ideal scaling was generated to fix this distortion, by modifying the volume in the SG plena and U-tubes. The results of this modification are shown in Figure 11. It can be observed that the time at which the hot leg is voided is now the same in both calculations. In addition, the depressurization of the primary system once the break is in single phase vapor flow presents now a very similar behavior. This is also a consequence of the change in the volume above the reactor coolant line. In a situation of single phase vapor flow through the break, the depressurization rate is strongly linked to the size of the steam bubble facing the break and thus, in this particular case, to the volume above the RCL (Freixa and Manera, 2011).

This hybrid case and the Ascó NPP present results in quite close agreement, in particular now the timing of the most relevant events is essentially the same. The break flow, the primary pressure, the UP and core water levels and the PCT display very similar results. However, the DC water level still presents significant differences that need to be addressed.

\subsubsection{RPV bypasses}

The evolution of the DC level depends strongly on the different bypass flows between the UH, DC and UP (Freixa and Manera, 2010). There are significant design differences between the two systems in terms of bypass location, flow area and flow resistance. In order to avoid any design distortion inflicted by the bypasses, the location, area and pressure losses of the ideal scaling nodalization have been replaced by those of the Ascó NPP model. Figure 12 compares the results of this new hybrid case with the Ascó NPP nodalization.

The DC level with and without the modified bypasses and the Ascó NPP model are shown in Figure 13. The evolution of the DC level has changed significantly with the modification, specially during the first 2000 seconds. During the first 500 seconds the DC remains completely full of water, this is different from both the previous hybrid and the Kv scaled calculation. On the other hand, during the core heat-up phase, the "bypasses" hybrid model displays a behaviour closer to the Ascó NPP simulation. All in all, it can be concluded that this hybrid nodalization does not completely explain the differences in the DC level evolution. Since the main phenomena parameters as system pressures, cladding temperatures, break flow and RPV water levels present a very close agreement (see Figure 12) and the different evolution of the DC can be affected by several parameters like loop seal configuration and DC geometry, no further hybrid calculations were carried out.

\subsection{CET versus PCT}

Once the scaling and design analysis has been carried out, it is interesting to analyze the capabilities of the NPP model to reproduce the specific phenomena of relevance of the present scenario, which is the relation between the CET and the PCT and the scatter of temperatures at the core exit depending on the location during the core heat up phase. Figure 14 displays the maximum PCT as function of the different CET responses for the Ascó NPP Kv scaled calculation and the LSTF scaled-up plus hybrid modifications (from Section 4.4.2). Both models present a similar behavior. The CET readings in the Ascó NPP are slightly slower in responding to a PCT rise than in the ITF model, this means that lower CET values are measured for the same PCT. However, the difference between the fastest and the most slow CET responses is the same. All in all, it can be concluded that the results obtained by the two models are almost equivalent, and that the Ascó NPP model is qualified to analyze this phenomenon.

\subsection{Realistic conditions in the Ascó NPP}

In the previous section the Ascó NPP model has been qualified to analyze the response of the plant to an SBLOCA at the hot leg. The SCUP methodology has shown that the nodalization is capable to reproduce the phenomenology involved in this type of scenario.

Nevertheless, the calculation with the NPP model was performed with boundary conditions equivalent to those of ROSA-2 Test 3. Some of these boundary conditions differ from the real conditions expected in the NPP. In order to perform a realistic safety assessment of the response of the power plant, the boundary conditions of the scenario have been slightly modified. The changes performed are summarized below: 


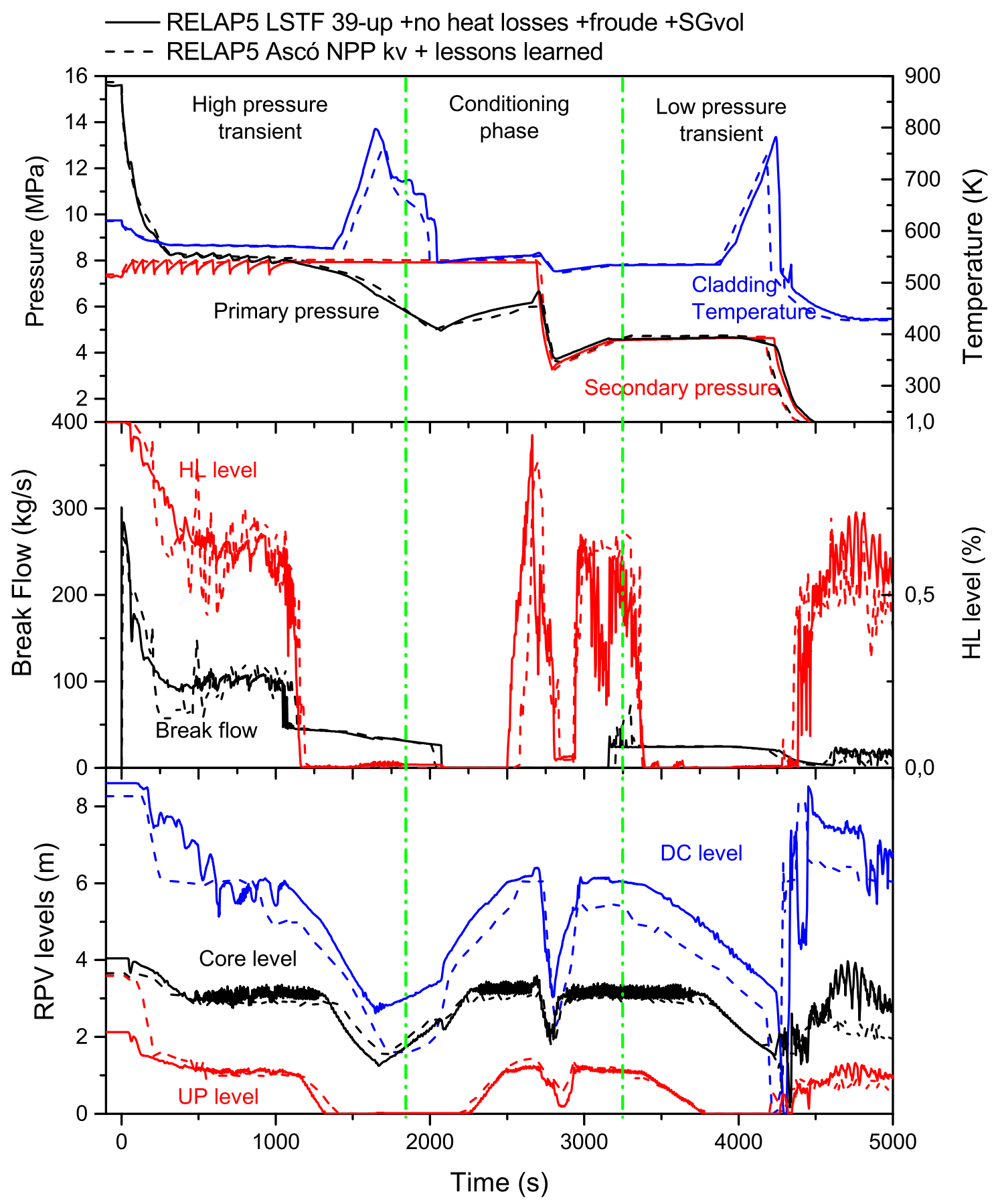

Figure 11: Comparison between the LSTF ideal scaled-up model (no heat losses, Froude number preserved and re-scaled SG volume) and the Kv scaled calculation (Ascó NPP). From top to bottom: (1) primary and secondary pressure along with the cladding temperature, (2) break flow and hot leg level close to the break location and (3) RPV collapsed water levels. 


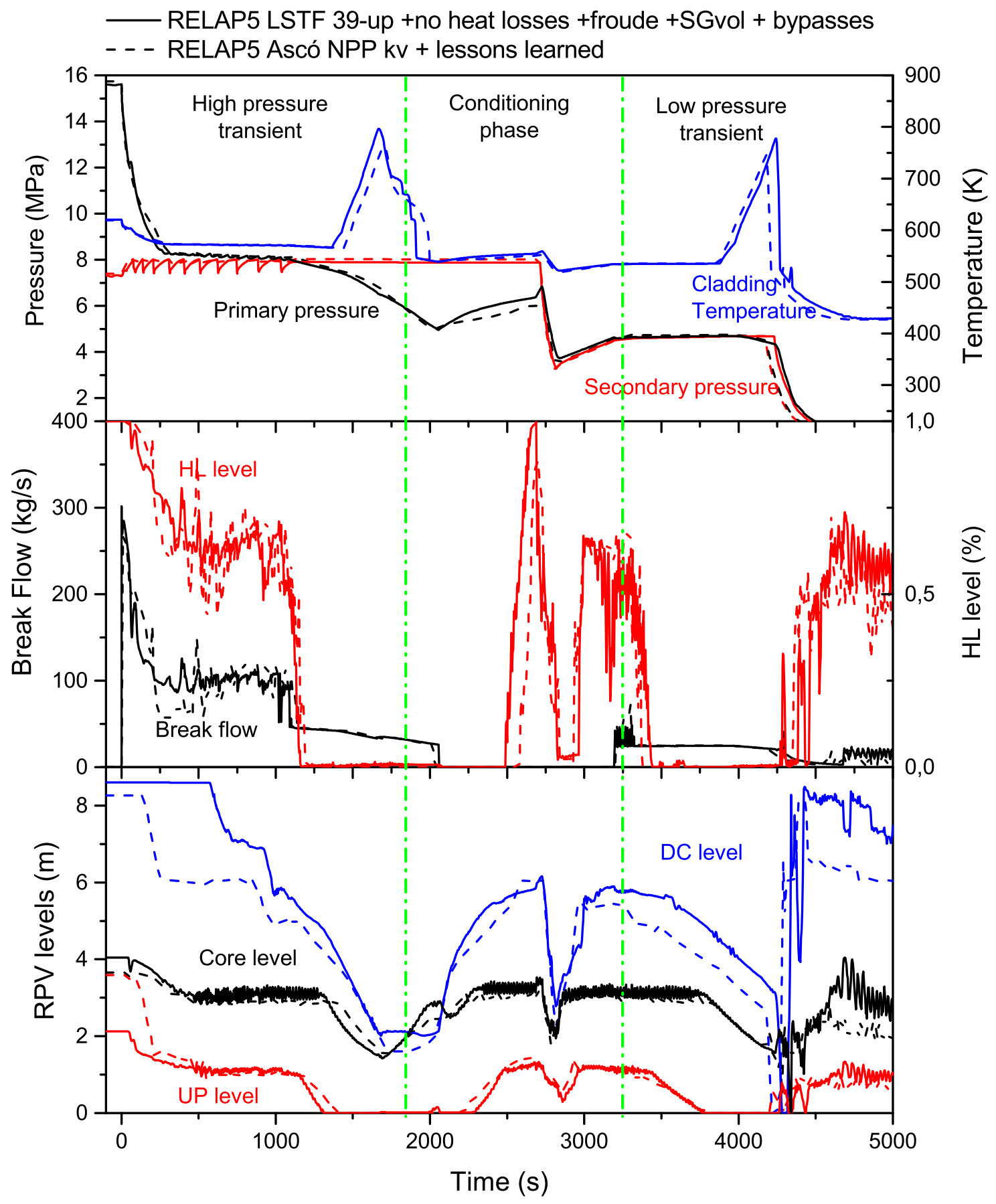

Figure 12: Comparison between the LSTF ideal scaled-up model (no heat losses, Froude number preserved, re-scaled SG volume and equivalent bypasses) and the Kv scaled calculation (Ascó NPP). From top to bottom: (1) primary and secondary pressure along with the cladding temperature, (2) break flow and hot leg level close to the break location and (3) RPV collapsed water levels. 


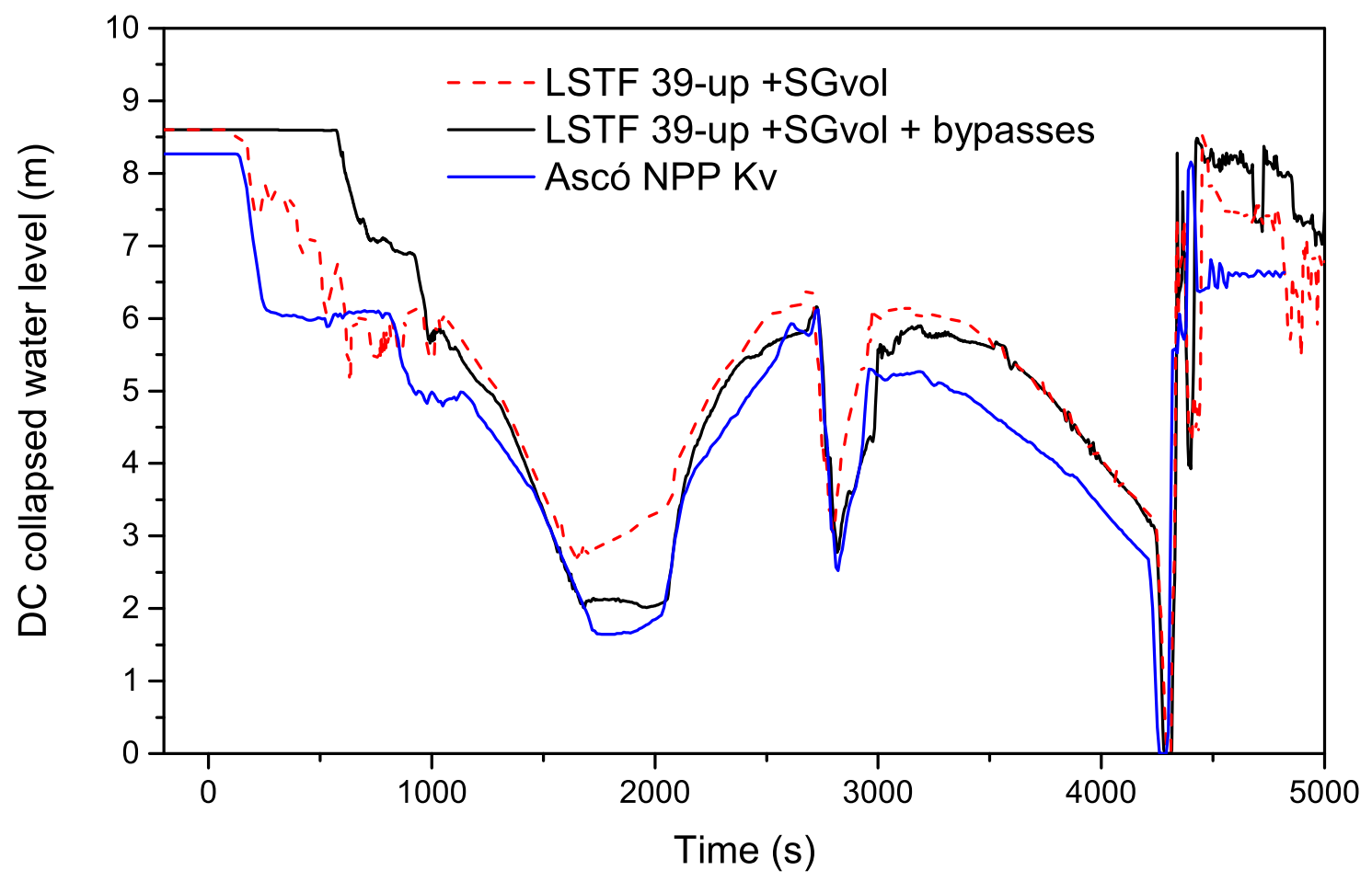

Figure 13: DC water level with the two hybrid ROSA/LSTF models compared to the Ascó NPP nodalization

- Point kinetics are used instead of a predefined power table.

- The coast down of the RCPs is based on the homologous curves of the Ascó NPP.

- The secondary relief valves set points and geometry are set to the original Ascó NPP conditions.

- Initial conditions are set to the original Ascó NPP initial conditions.

- The boundary conditions in order to manage the core heat-up scenario have been modified. Only the high pressure transient is simulated. In order to recover core cooling, the SG relief valves are fully opened when CET reaches $653 \mathrm{~K}$. This action is equivalent to the action in the low phase transient in the experiment. So the two calculations differ once a high CET is reached and cannot be compared from that moment.

In Figure 15, the main results of the realistic case are compared with the results of the scaling calculation. The differences between the two calculations are minor during the initial part of the transient and are mostly related to a different core power decrease at the time of scram. In addition, the secondary pressure from the start of the test until activation of AM is slightly higher in the realistic case since the set points for the SG relief valves are higher in Ascó NPP than in ROSA/LSTF. Therefore, the primary pressure remains slightly higher during the reflux-condensation phase (400-1200 seconds) and thus the break flow during this phase was also higher. The consequence is that the coolant in the loops was depleted earlier and hence core uncovery occurred about 100 seconds earlier. Once core uncovery takes place, the two calculations follow very different boundary conditions and thus the results cannot be compared. In the realistic scenario the SG relief valves are fully open when the maximum CET reaches $653 \mathrm{~K}$. In the experiment, the high pressure heatup scenario is managed through direct high pressure injection into the UP, the secondary depressurization AM is only performed for the low pressure transient. The action is performed in the realistic calculation 


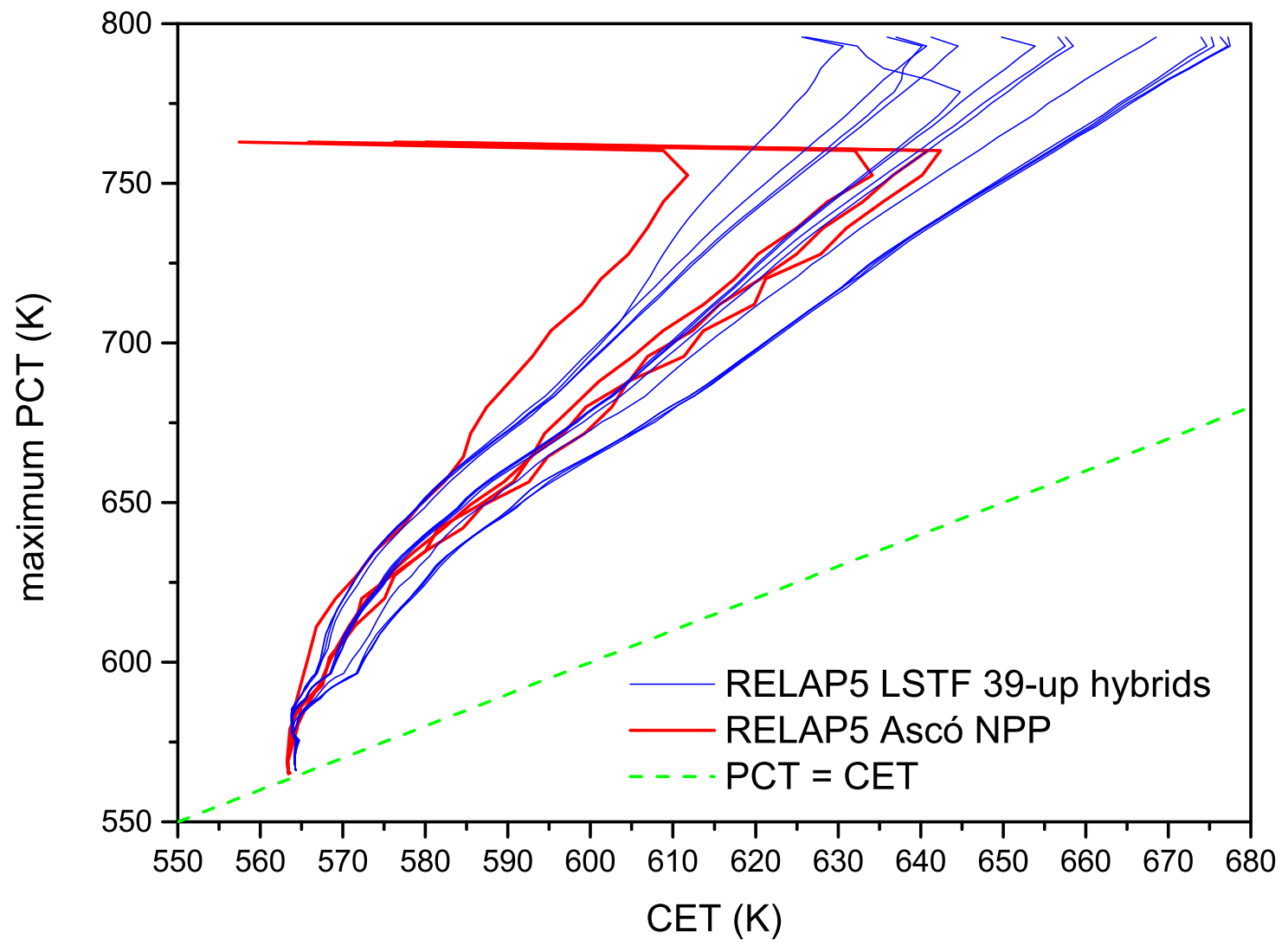

Figure 14: PCT as a function of the CET for Test 3 (LSTF scaled-up plus hybrids in comparison the Ascó NPP Kv scaled calculation) 
at around $1700 \mathrm{~s}$ and leads only to a mitigation of the core heat up, the core is only flooded when the Accumulators discharge is initiated.

It has been shown in the previous section that there is a certain scatter of the different CET locations. An additional calculation has been carried out where the minimum CET measurement is taken instead of the maximum. The consequence is a delay in the AM action to depressurize the secondary system. Figure 16 displays the PCT considering the two boundary conditions. The PCT when all the CET readings are credited is $872 \mathrm{~K}$, however, when only the minimum CET reading is credited the maximum temperature in the core rises to $1053 \mathrm{~K}$. 


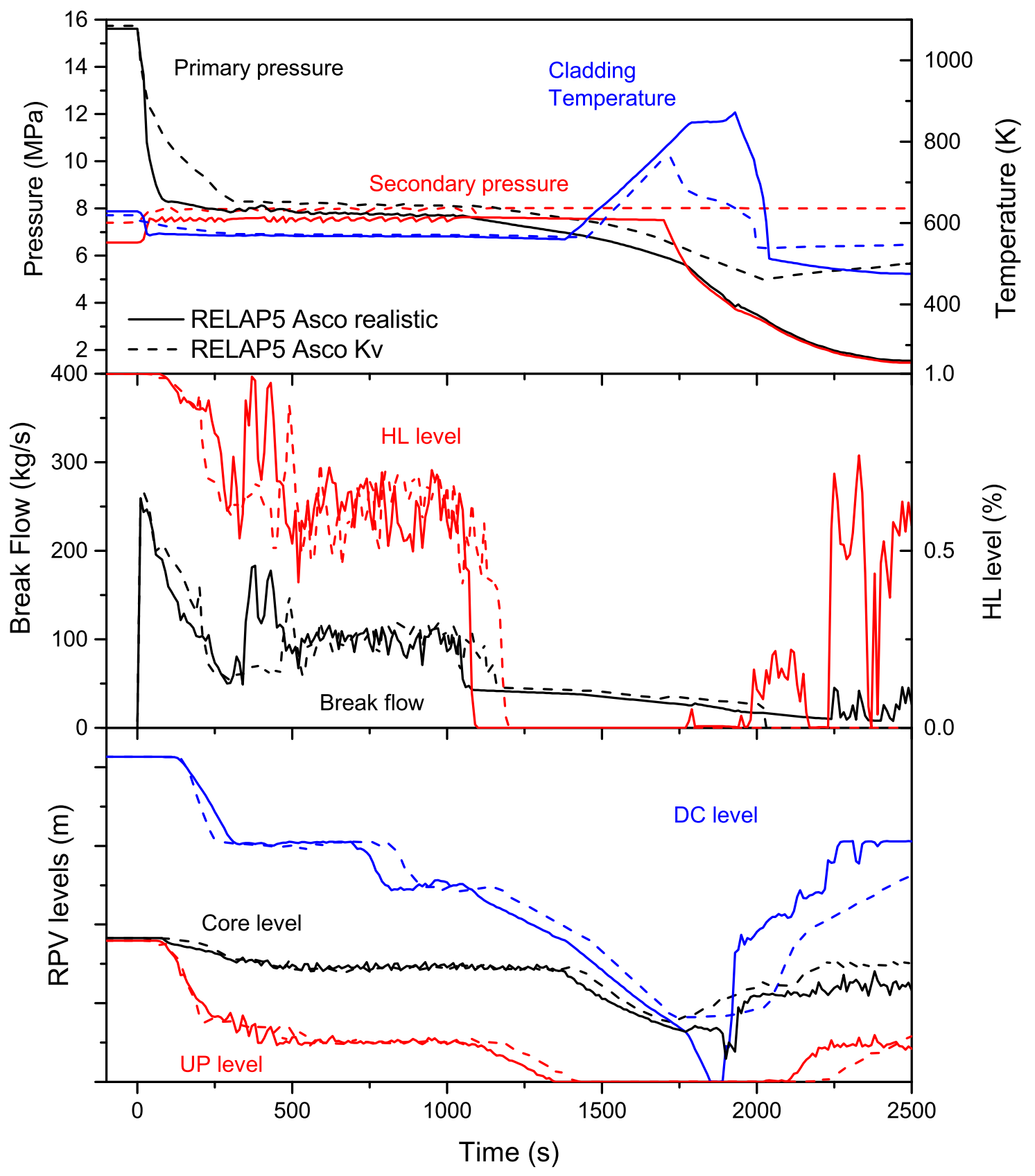

Figure 15: RELAP5 results of the Ascó NPP model with realistic boundary conditions. From top to bottom: (1) primary and secondary pressure along with the PCT, (2) break flow and hot leg level close to the break location, and (3) RPV collapsed water levels 


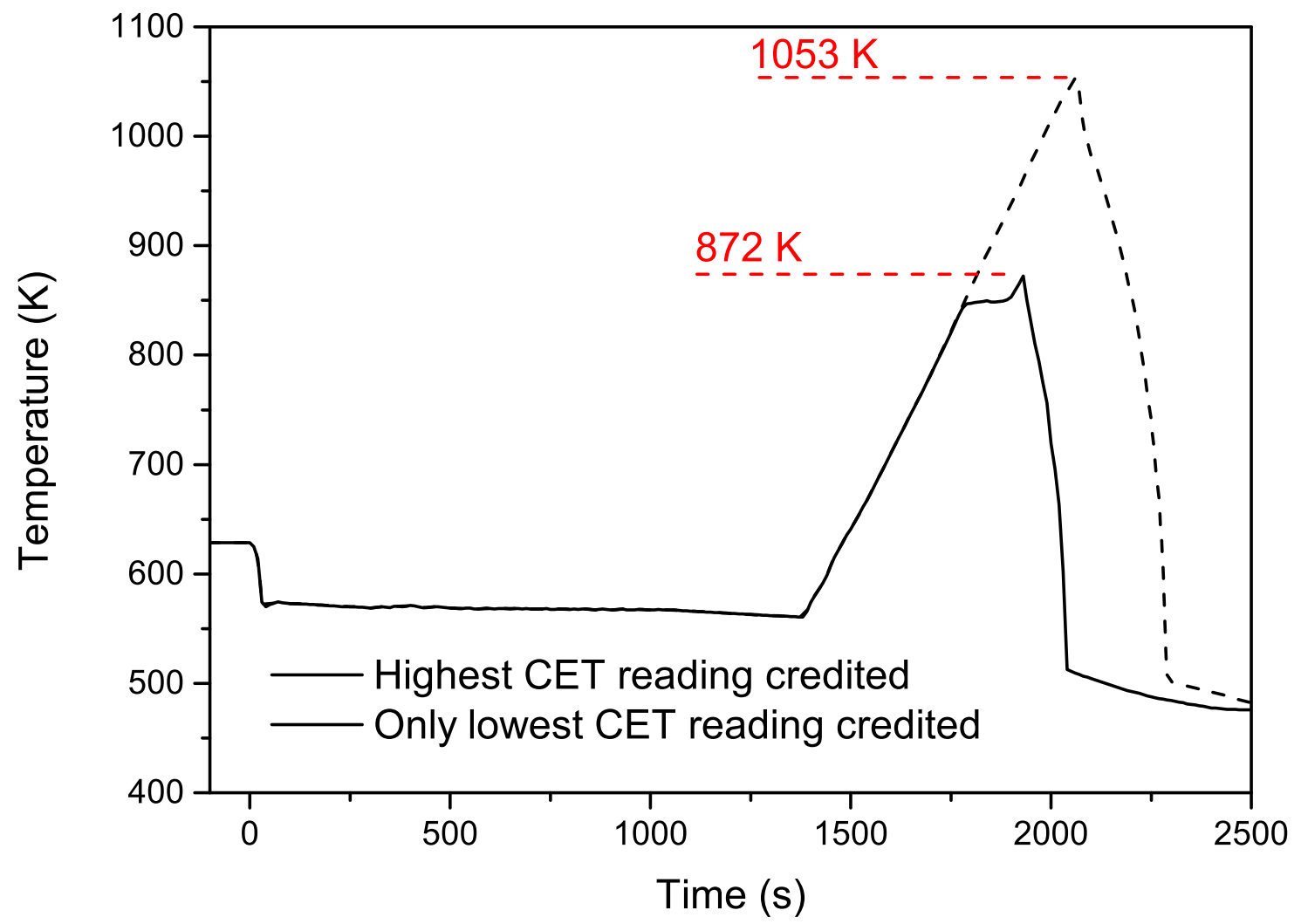

Figure 16: Evolution of the PCT in the Ascó NPP realistic scenario, two cases are shown:(1) the maximum value of the four CET measurements is taken for AM action and (2) the minimum of the CET measurements is considered for AM actuation 


\section{Conclusions}

Following the CSNI recommendations for further research on the effectiveness of the CET measurements in accident management of NPPs, analytical studies to assess the performance of RELAP5 and the nodalization approaches for CET predictions have been conducted. In particular, the analytical work has been possible through the participation to the international project OECD/NEA-ROSA-2 that featured an ITF experiment reproducing a hot leg SBLOCA scenario where the CET response was crucial.

The simulation of the experiment has allowed the group to understand the physical mechanisms that govern the differences between the CET and the PCT. Results of the post-test calculation of the ROSA-2 Test 3 have shown a good performance of the nodalization approach and that the CET response can be predicted with sufficient confidence by RELAP5.

In this paper a full plant RELAP5 nodalization has been qualified through the SCUP methodology which uses results and simulations from ITF experiments. The main principle of the SCUP methodology is to compare results of post-test and full plant nodalizations by eliminating the scale and design differences through a systematic procedure. Applying the SCUP methodology required the fulfillment of the following steps:

1. Post-test calculation of the ROSA-2 Test 3. The post-test calculation provide excellent agreement with the experimental data.

2. Scaling considerations between the two systems in order to define the power to volume scaling factor $(\mathrm{Kv})$. In this case a value of 39 has been selected.

3. Scaling up the post-test calculation with the selected Kv factor. The post-test input deck was scaled up to the size of the NPP. The small and large scale calculations reported equivalent results. In this step the scaling effect was analyzed.

4. Performing Kv scaled calculation with the Ascó NPP model. The same boundary and initial conditions of the experiment were introduced to the NPP nodalization and the results were compared with the post-test scaled-up simulation.

5. Performing hybrid cases in order to discard design distortions. The design distortions were analyzed in this step, it was shown that by correcting the Froude number in the hot legs, eliminating the heat losses and changing the volume of liquid in the primary loops was sufficient to justify the differences between the Kv scaled and the up-scaled calculations.

Once all of these steps were completed and no significant difference was present, the NPP nodalization was deemed to be qualified for the specific phenomenology.

The final step of the work presented was to adapt the boundary conditions to a corresponding event taking place at the Ascó NPP. This was done by mainly adding the nominal initial conditions, applying a point kinetics model in order to simulate the core power and the use of the homologous pump curves to define the RCP coast down. In addition, only the high pressure transient has been simulated and the AM action to mitigate the core heat up has been the full opening of the SG relief valves when the CET reached $653 \mathrm{~K}$. The final conclusions in terms of reactor safety from this final step are:

- The use of a multi-pipe approach brought forward the differences of the outlet core steam temperatures depending on the radial location. This shows that having several CET thermocouples in the NPP is crucial.

- The AM was only partly effective in cooling the core. The cladding temperature kept rising after the SG valves were opened and was only controlled once the Acc injection flooded the core.

- If the centrally located CET measurements are not credited, and the minimum of the CET responses is taken for AM indicator, the rise in PCT is expected to be about $150 \mathrm{~K}$ higher. 


\section{Acknowledgements}

The present work contains findings that were produced within the OECD/NEA ROSA-2. The authors are grateful to the Management Board for their consent to this publication. The authors also want to thank the Spanish Safety Council (CSN) that have funded this research.

\section{References}

Annunziato, A., Glaeser, H., Lillington, J., Marsili, P., Renault, C., Sjoberg, A., 1996. CSNI INTEGRAL TEST FACILITY VALIDATION MATRIX FOR THE ASSESSMENT OF THERMAL-HYDRAULIC CODES FOR LWR LOCAAND TRANSIENTS. Tech. Rep. NEA/CSNI/R(96)17, Committee on the Safety of Nuclear Installations, OECD, Nuclear Energy Agency.

D'Auria, F., Debrecin, N., Galassi, G. M., 1995. Outline of the uncertainty methodology based on accuracy extrapostion (UMAE). Nuclear Technology 109, 21-38.

D'Auria, F., Galassi, G., Oct. 2010. Scaling in nuclear reactor system thermal-hydraulics. Nuclear Engineering and Design 240 (10), 3267-3293.

URL http://linkinghub.elsevier.com/retrieve/pii/S0029549310004280

Freixa, J., Manera, A., 2010. Analysis of an RPV upper head SBLOCA at the ROSA facility using TRACE. Nuclear Engineering and Design 240 (7), $1779-1788$.

Freixa, J., Manera, A., 2011. Verification of a TRACE EPR ${ }^{\mathrm{TM}}$ model on the basis of a scaling calculation of an SBLOCA ROSA test. Nuclear Engineering and Design 241 (3), 888 - 896.

URL http://www.sciencedirect.com/science/article/pii/S0029549311000148

Freixa, J., Martínez-Quiroga, V., Zerkak, O., Reventós, F., 2015. Modelling guidelines for core exit temperature simulations with system codes. Nuclear Engineering and Design 286, 116-129.

URL http://linkinghub.elsevier.com/retrieve/pii/S0029549315000850

Ishii, M., Revankar, S., Leonardi, T., Dowlati, R., Bertodano, M., Babelli, I., Wang, W., Pokharna, H., Ransom, V., Viskanta, R., Han, J., 1998. The three-level scaling approach with application to the purdue university multi-dimensional integral test assembly (puma). Nuclear Engineering and Design 186 (1-2), $177-211$

URL http://www.sciencedirect.com/science/article/pii/S0029549398002222

Kremin, H., limprecht, H., Güneysu, R., Umminger, K., july 2001. Description of the PKL III Test Facility. Tech. rep., Framatome ANP report.

Martinez-Quiroga, V., Reventos, F., 2014. The Use of System Codes in Scaling Studies: Relevant Techniques for Qualifying NPP Nodalizations for Particular Scenarios. Science and Technology of Nuclear Installations 2014, 1-13. URL http://www.hindawi.com/journals/stni/2014/138745/

Martinez-Quiroga, V., Reventos, F., Freixa, J., 2014. Applying UPC Scaling-Up Methodology to the LSTF-PKL Counterpart Test. Science and Technology of Nuclear Installations 2014, 1-18.

URL http://www.hindawi.com/journals/stni/2014/292916/

Martinez-Quiroga, V., Reventos, F., Pretel, C., 2012a. Post-Test Calculation of the ROSA/LSTF Test 3-1 Using RELAP5/Mod3.3. Tech. Rep. NUREG/IA-409, USNRC.

URL http://pbadupws.nrc.gov/docs/ML1208/ML12083A011.pdf

Martinez-Quiroga, V., Reventos, F., Pretel, C., Lstf, R., Using, T., Mod, R., 2012b. Post-Test Calculation of the ROSA/LSTF Test 3-2 Using RELAP5/Mod3.3. Tech. Rep. NUREG/IA-0410, USNRC. URL http://pbadupws.nrc.gov/docs/ML1208/ML12083A012.pdf

Martínez-Quiroga, V., 2014. Scaling-up methodology, a systematical procedure for qualifying NPP nodalizations. Application to the OECD/NEA ROSA-2 and PKL-2 Counterpart test. Ph.D. thesis, Universitat Politècnica de Catalunya.

Navahandi, A., Castellana, S., Moradkhaniav, E., 1979. Scaling laws for modeling nuclear reactor systems (Nuclear Science and Engineering, 72).

Petelin, S., Mavko, B., Koncar, B., Hassan, Y. A., 2007. Scaling of the Small-Scale Thermal-Hydraulic Transient to the Real Nuclear Power Plant. Nuclear Technology 158(1), 56-68.

Pla, P., Reventós, F., Pretel, C., Giannotti, W., D'Auria, F., Annunziato, A., 2007. Code validation and scaling of the LOBI BL-30 experiment. In: ICCAP 2007. Nice, France.

Pretel, C., Batet, L., Cuadra, A., Machado, A., José, G. S., Sol, I., Reventós, F., 2001. Qualifying, validating and documenting a thermal-hydraulic code input deck. Workshop proceedings. Advanced thermal-hydraulic and neutronic codes: current and future applications. NEA/CSNI/R (2001) 22 (1), $239-250$.

Reventós, F., Batet, L., Llopis, C., Pretel, C., Salvat, M., Sol, I., 2007. Advanced qualification process of ANAV NPP integral dynamic models for supporting plant operation and control. Nuclear Engineering and Design 237 (1), $54-63$. URL http://www.sciencedirect.com/science/article/pii/S0029549306003694

Schoen, B., Schollengerger, S. P., Umminger, K., 2012. Test PKL III G7.1: SBLOCA with total failure of HPSI (Counterpart Testing with ROSA/LSTF) - Quick Look Report. Tech. Rep. PTCTP-G/2011/en/0008, Areva.

Takeda, T., Suzuki, M., Asaka, H., Nakamura, H., 2012. Quick-look Data Report of ROSA-2/LSTF Test 3 (Counterpart Test to PKL SB-HL-18 in JAEA). Tech. Rep. JAEA-Research 2012-, Japan Atomic Energy Agency.

The ROSA-V Group, 2003. ROSA-V Large Scale test facility (LSTF) system description for the third and fourth simulated fuel assemblies. Tech. Rep. JAERI-Tech 2003-037, Japan Atomic Energy Agency. 
Tóth, I., Prior, R., Sandervag, O., Umminger, K., Nakamura, H., Muellner, N., Cherubini, M., Del Nevo, A., D’Auria, F., Dreier, J., Alonso, J. R., Amri, A., October 2010. Core exit temperature (CET) effectiveness in accident management of nuclear power reactors. Tech. Rep. NEA/CSNI/R(2010)9, Committee on the Safety of Nuclear Installations, OECD, Nuclear Energy Agency.

Zuber, N., 1991. Hierarchical, two-tiered scaling analysis, Appendix D to an integrated structure and scaling methodology for sever accident technical issue resolution. Tech. Rep. (NUREG/CR-5809, EGG-2659), United States Nuclear Regulatory Commission.

Zuber, N., Wulf, W., Rohatgi, U. S., Catton, I., 2005. Application of fractional scaling analysis (FSA) to loss of coolant accidents (LOCA). Part 1: methodology development. The 11th International Topical Meeting on Nuclear Reactor Thermal Hydraulics (NURETH-11), Avignon, France. 